\title{
Long-term global distribution of Earth's shortwave radiation budget at the top of atmosphere
}

\author{
N. Hatzianastassiou ${ }^{1,2}$, A. Fotiadi ${ }^{2}$, C. Matsoukas ${ }^{2}$, K. G. Pavlakis ${ }^{2}$, E. Drakakis ${ }^{2,4}$, D. Hatzidimitriou ${ }^{2,3}$, and \\ I. $\operatorname{Vardavas}^{2,3}$ \\ ${ }^{1}$ Laboratory of Meteorology, Department of Physics, University of Ioannina, Greece \\ ${ }^{2}$ Foundation for Research and Technology-Hellas, Heraklion, Crete, Greece \\ ${ }^{3}$ Department of Physics, University of Crete, Crete, Greece \\ ${ }^{4}$ Department of Electrical Engineering, Technological Educational Institute of Crete, Greece
}

Received: 12 February 2004 - Published in Atmos. Chem. Phys. Discuss.: 14 May 2004

Revised: 16 July 2004 - Accepted: 23 July 2004 - Published: 3 August 2004

\begin{abstract}
The mean monthly shortwave (SW) radiation budget at the top of atmosphere (TOA) was computed on $2.5^{\circ}$ longitude-latitude resolution for the 14-year period from 1984 to 1997 , using a radiative transfer model with long-term climatological data from the International Satellite Cloud Climatology Project (ISCCP-D2) supplemented by data from the National Centers for Environmental Prediction - National Center for Atmospheric Research (NCEP-NCAR) Global Reanalysis project, and other global data bases such as TIROS Operational Vertical Sounder (TOVS) and Global Aerosol Data Set (GADS). The model radiative fluxes at TOA were validated against Earth Radiation Budget Experiment (ERBE) S4 scanner satellite data (1985-1989). The model is able to predict the seasonal and geographical variation of SW TOA fluxes. On a mean annual and global basis, the model is in very good agreement with ERBE, overestimating the outgoing SW radiation at TOA (OSR) by $0.93 \mathrm{Wm}^{-2}$ (or by $0.92 \%$ ), within the ERBE uncertainties. At pixel level, the OSR differences between model and ERBE are mostly within $\pm 10 \mathrm{Wm}^{-2}$, with $\pm 5 \mathrm{Wm}^{-2}$ over extended regions, while there exist some geographic areas with differences of up to $40 \mathrm{Wm}^{-2}$, associated with uncertainties in cloud properties and surface albedo. The 14-year average model results give a planetary albedo equal to $29.6 \%$ and a TOA OSR flux of $101.2 \mathrm{Wm}^{-2}$. A significant linearly decreasing trend in OSR and planetary albedo was found, equal to $2.3 \mathrm{Wm}^{-2}$ and $0.6 \%$ (in absolute values), respectively, over the 14-year period (from January 1984 to December 1997), indicating an increasing solar planetary warming. This planetary SW radiative heating occurs in the tropical and sub-tropical areas $\left(20^{\circ} \mathrm{S}-20^{\circ} \mathrm{N}\right)$, with clouds being the
\end{abstract}

Correspondence to: N. Hatzianastassiou

(nhatzian@cc.uoi.gr) most likely cause. The computed global mean OSR anomaly ranges within $\pm 4 \mathrm{Wm}^{-2}$, with signals from El Niño and La Niña events or Pinatubo eruption, whereas significant negative OSR anomalies, starting from year 1992, are also detected.

\section{Introduction}

The sun is the source of energy that sustains life on the Earth. Solar energy enters and is redistributed within the Earthatmosphere system, which subsequently emits radiation at longer wavelengths. The Earth's radiation budget (ERB) drives the general circulation of the atmosphere and determines the climate of the Earth-atmosphere system, being an indicator of possible climatic changes. Thus, it is very important to be able to determine as accurately as possible its components at the top of atmosphere (TOA), within the atmosphere and at the Earth's surface for both shortwave (SW) and longwave (LW) radiative fluxes. At TOA, the net energy input is determined by the incident $\mathrm{SW}$ radiation from the Sun minus the reflected SW energy. The difference defines the net SW radiative flux at TOA. To balance this inflow of SW energy, the Earth-atmosphere system emits LW radiation to space. For the planet to be in radiative equilibrium, the emitted LW radiation must equal the net inflow of SW radiation at TOA. However, satellite observations such as the 5-year (1985-1989) Earth Radiation Budget Experiment (ERBE) scanner (Kiehl and Trenberth, 1997) or Nimbus-7 (Ardanuy et al., 1992) data, as well as most model estimates (e.g. Yu et al., 1999) indicate non-radiative equilibrium at TOA, implying a net radiative heating of the planet by about $3 \mathrm{Wm}^{-2}$ or even larger. Thus, more and detailed studies are 
needed to further investigate the radiation budget at TOA, where the model results can be used as first estimates, even though their accuracy is limited.

Since the first energy budgets (Abbot and Fowle, 1908; Dines et al., 1917) there have been a number of early studies (e.g. Houghton, 1954; Budyko, 1956; London, 1957), but most of them were severely limited by the lack of knowledge of planetary albedo. Early estimates of planetary albedo ranged from $40 \%$ to $50 \%$ (see Hunt et al., 1986 for a review of these early studies). Satellite observations from Nimbus7 and ERBE have greatly improved estimates of planetary albedo, indicating values near $30 \%$. Although the determination of radiative fluxes at TOA is much more advanced than at surface, due to the recent advances in space-borne measurements that provide good knowledge of the net solar energy absorbed by the global climate system (Barkstrom et al., 1989), there is a need to improve our ability to compute accurately the ERB at TOA by using models. Model validation at TOA is a prerequisite for obtaining reliable model computations of ERB at the surface, where direct satellite measurements are not possible and surface measurements cannot provide complete global coverage. Satellite observations of ERB have limitations in their accuracy (Li et al., 1997), and do not provide continuous data. An outgoing SW radiation (OSR) data set has been produced from the ERB measurements taken aboard Nimbus satellites (Jacobowitz et al., 1984; Kyle et al., 1985, 1993). The Nimbus ERB scanner data cover the period from January 1979 through May 1980, while non-scanner data extend from November 1978 till December 1993. The ERBE results (Barkstrom, 1984; Barkstrom and Smith, 1986; Barkstrom et al., 1989) are believed to give the most definitive TOA radiation. The ERBE scanner OSR data are considered to be of very good quality in terms of spatial and temporal coverage and instrument accuracy, but they cover only the 5-year period from November 1984 to February 1990. Therefore, although the ERB data obtained from the Nimbus-7 measurements along with those from ERBE, span over a decade (1978-1990), they do not provide continuity. Beyond this, there is some gap in time series between those and more recent accurate measurements, such as the Scanner for Radiation Budget (ScaRaB, Kandel et al., 1998) and the Clouds and the Earth's Radiant Energy System (CERES, Wielicki et al., 1996), especially during the 1990s. In addition, comparisons between different ERB datasets show differences (e.g. Hartmann et al., 1986) that can be very important and comparable in magnitude to the radiative forcing of climatic change factors. More sophisticated space-borne instruments such as the Moderate Resolution Imaging Spectro-radiometer (MODIS) on board the Terra and Aqua Satellites and the Geostationary Earth Radiation Budget (GERB) instrument on EUMETSAT's Meteosat Second Generation (MSG) satellite (Sandford et al., 2003) have started high-accuracy and high-resolution measurements since early 2000. Furthermore, apart from the fact that satellite measurements have their own errors, espe- cially the SW retrievals (Kiehl and Briegleb, 1997), they do not provide complete spatial (global) coverage, as they often miss areas poleward of $70^{\circ}$ latitude, where model results can be used as first estimates, even though not very accurate. Reliable model ERB computations at TOA, are very important to the study of the temporal variation of the Earth's radiation budget and help to understand the physical processes that determine the TOA radiation budget.

To date, very few modelling studies have been performed that reproduce successfully the spatial and temporal distribution of the SW radiation budget (SWRB) at TOA. To achieve this, a complete description of the processes that govern the transfer of solar radiation within the Earth-atmosphere system is required together with comprehensive global data sets for the key surface and atmospheric parameters. Early models for atmospheric radiation transfer attempted to predict the TOA SWRB (e.g. London and Sasamori, 1972; Ohring and Adler, 1978; Stephens et al., 1981; Peng et al., 1982) but they suffered from the lack of reliable model input data with global coverage, since they used mostly surface-based data. The availability of accurate global satellite data of cloud, atmospheric and surface properties has made modelling more reliable. At the same time, validation of model TOA SWRB results has become possible through comparison against available comprehensive data, such as those of ERBE. A few studies dealing with TOA SWRB were published (Sasamori et al., 1972; Ellis and Vonder Haar, 1976; Jacobowitz et al., 1979; Ohring and Gruber, 1983; Jacobowitz et al., 1984) but mostly on a mean zonal or global basis, and covering relatively short time periods. Moreover, comparisons between model results and satellite data, have shown rather large deviations (see Rossow and Zhang, 1995) of up to $2 \%$ in planetary albedo. More recent model computations such as those given by Rossow and Zhang (1995), and Hatzianastassiou and Vardavas $(1999,2001)$, provided better agreement with satellite measurements at TOA, but for relatively short time periods (1984 through 1990) and on mean latitude-zonal basis. On the other hand, published results (e.g. Kyle et al., 1990, 1993; Li et al., 1997; Yu et al., 1999; Ho et al., 2002) indicate significant discrepancies between model results and satellite data or even between different satellite data. In addition, global circulation models (GCMs) still have difficulties in computing the TOA SWRB components, especially under all-sky (clear plus cloudy sky) conditions (Harshvardhan et al., 1989; Kiehl et al., 1994; Ridout et al., 1994; Chen and Roeckner, 1996; Fowler et al., 2000; Loeb et al., 2002). Furthermore, although data from global reanalyses projects give good results for the TOA SWRB for clear-skies, they fail under all-sky conditions (Yang et al., 1999).

In this study, a deterministic radiative transfer model is used to compute the global distribution of all TOA shortwave radiation budget components on a mean monthly and $2.5^{\circ}$ by $2.5^{\circ}$ longitude-latitude resolution, spanning the 14 -year period from January 1984 through December 1997. A detailed 
summary of all relevant parameters is given, with emphasis on patterns of average parameter values over space and time, specific local and temporal characteristics, and inter-annual variability. The model uses data from the International Satellite Cloud Climatology Project (ISCCP) D2-series (Rossow et al., 1996). The ISCCP, which is currently the most extensive and comprehensive global cloud climatology, provides model input data not only for clouds, but also for other surface and atmospheric parameters (see Sect. 3). The data from ISCCP were supplemented by water vapour and temperature data taken from the National Centers for Environmental Prediction (NCEP) and National Center for Atmospheric Research (NCAR) Global Reanalysis Project. Model input data were also taken from other global databases, such as the Television Infrared Observational Satellite (TIROS) Operational Vertical Sounder (TOVS), the International Satellite Land Surface Climatology Project (ISLSCP), and the Global Aerosol Data Set (GADS), as explained in Sect. 2. The model computations are validated at pixel-level, against 5-year accurate scanner data from ERBE, which ensures the quality of the long-term model results. In the next section, we describe the model, while Sect. 3 describes the model input data and the satellite data used for the validation of the model. The model results are given in Sect. 4, where patterns of seasonal and temporal distributions of SWRB components are discussed on the basis of pixel-level model results, while mean hemispherical and global as well as mean annual radiative flux computations are presented and interannual trends are examined. An assessment of the sensitivity of TOA SWRB to the various key surface and atmospheric physical parameters is also given in Sect. 4, before the summary and conclusions.

\section{Model description}

The radiative transfer model used divides the SW radiation into two spectral bands, one for the ultraviolet-visible (UV-visible) wavelengths $(\lambda<0.85 \mu \mathrm{m})$ accounting for about $60 \%$ of total solar radiation, and a second band for the near-infrared (near-IR) wavelengths $(0.85 \mu \mathrm{m} \leq \lambda \leq 5 \mu \mathrm{m})$ accounting for about $40 \%$ of total solar radiation. The model achieves a compromise between accuracy of spectral model computations and speed of computation of parameterization schemes. The range of uncertainty of the model has been tested by comparing the model results with those of lineby-line computations for various atmospheric conditions, according to the Intercomparison of Radiation Codes in Climate Models (ICRCCM) program (Fouquart et al., 1991). The model results were found to be different to those of lineby-line models by up to $7 \%$. Of course, spectral models perform always better and have higher accuracy, but they demand much longer computing time, which makes them difficult to use routinely. The model was developed from a detailed spectral radiative-convective model (see Vardavas and
Carver, 1984) that uses the modified delta-Eddington method to perform the multiple scattering in the ultraviolet-visible region, and in the solar near-infrared region to allow for cloud absorption/scattering and molecular absorption by water vapour, carbon dioxide and methane. The present simpler model has been used by Vardavas and Koutoulaki (1995) and Hatzianastassiou and Vardavas $(1999,2001)$ to compute the SW radiation budget of northern and southern hemispheres on a mean monthly and $10^{\circ}$ latitude zonal basis. Here, the mean monthly incoming total solar flux at TOA for each $2.5^{\circ}$ latitude-longitude pixel, is computed by summing the corresponding mean daily flux on day $n$, given by

$F_{\text {top }}^{\downarrow}=S_{0} \mu_{n} d_{n} / r^{2}$,

where $\mu_{n}$ is the cosine of the mean daily solar zenith angle, $S_{0}$ is the solar constant $\left(1367 \mathrm{Wm}^{-2}\right.$, Frölich, 1983; Hartmann, 1994; Willson, 1997), $d_{n}$ is the daylength, and $1 / r^{2}$ is a correction factor due to the Earth's elliptical orbit around the Sun. The daylength is given by

$d_{n}=8.64 \cdot 10^{4} H_{n} / \pi$,

where the hour angle $\mathrm{H}_{n}$ is given by

$H_{n}=\cos ^{-1}\left(-\tan \theta \cdot \tan \delta_{n}\right)$

with $\theta$ the latitude of a given location on Earth and $\delta_{n}$ the solar declination computed from

$\delta_{n}=\arcsin \left(0.39779 \sin \lambda_{n}\right)$

with

$\lambda_{n}=L_{n}+1.915 \sin g_{n}$

$L_{n}=280.46+K_{n}+0.0077(y r-2000)$

$g_{n}=357.53+K_{n}-0.0095(y r-2000)$

$K_{n}=360(n-1+t / 24) / 365$

where $y r$ is the year (Astronomical Almanac, 1991). The mean daily solar zenith angle is given by

$\mu_{n}=A_{n}+B_{n} \sin H_{n} / H_{n}$

with

$A_{n}=\sin \theta \cdot \sin \delta_{n}$

$B_{n}=\cos \theta \cdot \cos \delta_{n}$

The computed incoming solar radiation at TOA for each month and $2.5^{\circ}$ pixel was compared successfully against 5year scanner S4 data from ERBE (model-ERBE differences within $2.5 \mathrm{Wm}^{-2}$ ) and is divided into the UV-visible and near-IR spectral bands. The solar radiative transfer in the Earth-atmosphere system is treated separately in each spectral band and accounts for absorption and multiple scattering. The atmosphere is divided into five types of layers that 
affect significantly the solar radiation transfer, apart from cloud layers. The five layers are: ozone $\left(\mathrm{O}_{3}\right)$ layer, water vapour layer, carbon dioxide $\left(\mathrm{CO}_{2}\right)$ layer, aerosol layer and Rayleigh scattering layer. For each pixel, the sky is divided into clear and cloudy fractions, and hence direct and diffuse components are considered for solar radiation. In the clearsky atmosphere, the UV-visible component of solar radiation undergoes absorption by the $\mathrm{O}_{3}$ layer, and Rayleigh scattering by air molecules and aerosol particles, while the near-IR component undergoes absorption by water vapour, aerosol particles and $\mathrm{CO}_{2}$. Above the clouds there are $\mathrm{O}_{3}$ and $\mathrm{CO}_{2}$ layers, while below there are water vapour and $\mathrm{CO}_{2}$ layers, all above an isotropically reflecting Earth surface. The total fraction of the sky covered by clouds is taken to comprise three non-overlapping low, mid and high-level cloud components. The direct component of solar radiation is characterised by a $\mu=\operatorname{cosz}$ ( $\mathrm{z}$ is the solar zenith angle) which depends on latitude and on time of year. The diffuse solar radiation is characterised by $\mu=3 / 5$, the standard diffusivity approximation for converting diffuse transmission to an equivalent direct transmission.

The net incoming solar radiation at TOA (planetary absorption), $F_{\text {net, top }}^{\downarrow}$, the outgoing SW radiation (OSR) at TOA, $F_{\text {top }}^{\uparrow}$, and the planetary albedo $R_{p}$, are computed from

$F_{\text {net }, \text { top }}^{\downarrow}=\alpha_{p} F_{\text {top }}^{\downarrow}$

$F_{\text {top }}^{\uparrow}=\left(1-\alpha_{p}\right) F_{\text {top }}^{\downarrow}$

$R_{p}=\frac{F_{t o p}^{\uparrow}}{F_{t o p}^{\downarrow}}$,

where $\alpha_{p}$ is the planetary absorptivity. The scattering and absorption of the incoming SW radiation at TOA, depends strongly on the presence and type of clouds in the atmosphere, the composition of the atmosphere (gases plus particulate matter) and the reflectivity of the Earth's surface. It is weakly dependent on the thermal structure of the atmosphere. The cloudy sky component is subdivided into components covered by low, middle, and high-level clouds. The planetary absorptivity, and hence the OSR (Eq. 13), has a clear-sky component, $\alpha_{s}$, and three cloudy-sky components, $\alpha_{c i}$, and is expressed as

$\alpha_{p}=\left(1-A_{c}\right) \alpha_{s}+\sum_{i} A_{c i} \alpha_{c i}$

Both clear- and cloudy-sky components are computed by dividing the incoming solar radiation into UV-visible and near-IR components, based on estimated transmissivities, absorptivities, and reflectivities of the different atmospheric and cloud layers and the Earth's surface (see Vardavas and Koutoulaki, 1995; Hatzianastassiou and Vardavas, 1999, 2001).
The reflectivity, transmissivity and absorptivity of each of the various atmospheric layers, such as $\mathrm{O}_{3}, \mathrm{CO}_{2}$, water vapour, Rayleigh, are computed by using parameterisations derived from laboratory measurements (Vardavas and Koutoulaki, 1995). More specifically, absorption by $\mathrm{O}_{3}$ in the visible between 0.45 and $0.85 \mu \mathrm{m}$ (Chappuis bands) is taken into account by the model. The $\mathrm{O}_{3}$ layer also absorbs UV radiation between 0.2 and $0.35 \mu \mathrm{m}$ (Hartley-Huggins bands). The absorption of solar radiation by $\mathrm{CO}_{2}$ takes place throughout the atmosphere. We neglect the UV absorption by $\mathrm{CO}_{2}$, which occurs below $0.2 \mu \mathrm{m}$, where the solar flux is less than $0.01 \%$ of the total incoming solar flux, while $\mathrm{CO}_{2}$ absorption in the near-IR is accounted for in the model. The water vapour absorption, which has significant bands in the near-IR, is parameterised in the model as in Vardavas and Koutoulaki (1995).

For each cloud and aerosol layer, computations are performed using two-stream approximation for purely scattering clouds in the UV-visible, and a modified two-stream approximation allowing for cloud absorption in the near-IR (Vardavas and Koutoulaki, 1995; Hatzianastassiou and Vardavas, 1999) and for aerosol absorption in the UV-visible. For clear sky, Rayleigh scattering is taken into account by the model in the UV-visible, while it is neglected for the near-IR component, given that the Rayleigh scattering cross-section decreases rapidly with wavelength. For a cloudy sky, Rayleigh scattering is neglected since cloud optical depth is much larger than the Rayleigh scattering optical depth.

Reflection of incident solar radiation from the Earth's surface is taken into account and the surface reflectivity, $R_{g}$, for each $2.5^{\circ}$ pixel, is computed considering four general types of surface: land, ocean, snow and ice (frozen ocean). Then

$$
R_{g}=f_{\text {land }} R_{\text {land }}+f_{\text {ocean }} R_{o}+f_{\text {snow }} R_{s}+f_{\text {ice }} R_{i}
$$

where $f_{i}$ is the fractional coverage of the pixel's surface by each type $-\mathrm{i}$ of reflecting surface. The ocean reflectivity, $R_{o}$, is computed using Fresnel reflection corrected for a nonsmooth surface for an incident angle $\phi=\cos ^{-1} \mu$ from

$R_{o}=0.5\left[\left(\frac{\sin a}{\sin b}\right)^{2}+\left(\frac{\tan a}{\tan b}\right)^{2}\right]+0.016 \cos \varphi$

where

$a=\varphi-\sin ^{-1}[\sin \varphi / 1.333]$

$b=2 \varphi-\alpha$

For incident solar radiation onto a perfectly smooth water surface, the angle of reflection equals that of incidence, and for normal incidence the reflectivity is 0.024 . For an ocean we correct the Fresnel reflectivity to take into account surface roughness, which leads to a higher surface reflectivity of about 0.04 for incident solar radiation normal to the water surface (Kondratyev, 1973). The correction factor $0.016 \cos \phi$ 
goes to zero when the radiation is parallel to the ocean surface in order to maintain a Fresnel reflectivity of unity in this case. Further, we include the condition that if Fresnel reflectivity is greater than ice- or snow reflectivity, which occurs for low solar elevations, then the reflectivities of ice or snow are set equal to the Fresnel one. Kuhn (1989) gives observations that clearly show this behaviour for snow cover in Antarctica.

Snow albedo, $R_{S}$, is set equal to 0.85 and 0.65 (Dickinson et al., 1993) in the UV-visible and near-IR, respectively, while sea-ice albedo, $R_{i}$, is set equal to 0.7 and 0.5 (Roesch et al., 2002) in the UV-visible and near-IR, respectively, based on recent estimates. Given that land shows a strong spatial variability in terms of its type and associated reflectance values, the data used were derived from ERBE data for clear sky, while overcast albedos were obtained by modifying the corresponding clear-sky values for diffuse radiation conditions (Darnell et al., 1992). Alternatively, the land surface albedo was also computed based on information on land cover, taken from the International Satellite Land Surface Climatology Project (ISLSCP, Sellers et al., 1995). The ISLSCP data were produced for the 24-month period (1987-1988) and are mapped to $1^{\circ}$ by $1^{\circ}$ spatial resolution, with a mean monthly temporal resolution. They describe the geographical distribution of major cover types, based on inter-annual variation of Normalized Difference Vegetation Index (NDVI). Information for fractional coverage for each surface type (land, ocean, snow, ice) is obtained from ISCCP-D2 data (Rossow et al., 1996), whereas suitable reflectivity values for each surface type are ascribed, based on values taken from literature (Henderson-Sellers and Wilson, 1983; Briegleb et al., 1986), which allow for spectral dependence over the UV-visible and near-IR range of wavelengths, which is very important (Wei et al., 2001), but also allow for different values for the direct and diffuse components of solar radiation. Over mountainous non-forested areas, the surface albedo was found to be overestimated, especially during winter, due to various reasons relevant to sub-grid orography, as explained by Roesch et al. (2001). Thus, in a first simple approach, we applied a correction to land-surface albedo for high-altitude mountainous areas such as Tibet, Rocky Mountains or Anartcica's plateau, by reducing the albedo, which led to a significant improvement, as explained in Sect. 4.1.

\section{The model data}

\subsection{Ozone and carbon dioxide}

The mean monthly $2.5^{\circ}$ latitude-longitude pixel data of the total $\mathrm{O}_{3}$ column abundance (in Dobson Units) for years 1984-1997, were taken from the Television Infrared Observational Satellite (TIROS) Operational Vertical Sounder (TOVS), archived in the ISCCP-D2 package. For $\mathrm{CO}_{2}$ a fixed total atmospheric amount was taken, equal to $0.54 \mathrm{~g} \mathrm{~cm}^{-2}$, corresponding to 345 parts per million by volume (ppmv).

\subsection{Water vapour}

The water vapour data used were taken from the NCEP/NCAR Global Reanalysis Project, which provides long-term (1948-continuing) climatological data. The data for specific humidity and atmospheric temperature were used to compute the total atmospheric water vapour content, $\mathrm{W}_{\mathrm{H} 2 \mathrm{O}}$. The gridded NCEP/NCAR data are provided at surface and various atmospheric levels that extend from surface up to the stratosphere. Relative humidity data were also used to compute the humidity of the aerosol layer. The model was also run using corresponding data taken from the European Center for Medium range Weather Forecast (ECMWF) ERA15 Reanalysis Project. The differences in terms of TOA SW radiative fluxes were found to be small (mostly within 1$2 \mathrm{Wm}^{-2}$ at pixel level), as also discussed in Sect. 4 .

\subsection{Clouds}

Mean monthly cloud properties on $2.5^{\circ}$ equal-angle pixel resolution for the study period (1984-1997) are taken from the latest D2 stage data of ISCCP, which are improvements over the previous C-series version (Rossow and Schiffer, 1999). The ISCCP provides currently the most extensive and comprehensive cloud climatological database that quantifies the variations of cloud properties at global scale for the period starting from 1984 and still continuing. The most significant changes in the new D-series are: i) revised radiance calibrations to remove spurious changes in the long-term record, ii) increased Cirrus detection sensitivity over land, iii) increased low-level cloud detection sensitivity in polar regions, iv) improved cold cloud (cloud-top temperature $<260^{\circ} \mathrm{K}$ ) properties using an ice crystal microphysics model in place of a liquid droplet microphysics model, and v) increased detail about variations of cloud properties. Cloud properties are provided from ISCCP for nine cloud types which are grouped into three categories: low-level clouds having top pressures greater than or equal to $680 \mathrm{mbar}$, high-level clouds with top pressures less than 440 mbar and mid-level clouds in between (Rossow et al., 1996). Low-level clouds are considered to be $\mathrm{Cu}, \mathrm{St}$ and Sc clouds. The middle ones include Ac, As and Ns, while $\mathrm{Ci}, \mathrm{Cs}$ and deep-convective clouds are considered as high-level clouds. High clouds are treated as cold clouds, while each of the above low and middle clouds are subdivided into liquid- or ice-phase clouds, resulting in 15 cloud types for which properties such as cloud cover, cloud optical thickness, cloud-top temperature and pressure, as well as liquid or ice water path are provided by ISCCP-D2. The values for the 15 independent cloud types were then appropriately averaged (see Hatzianastassiou and Vardavas, 1999) to yield data for low, mid and high-level clouds assumed in our model. 
Table 1. Computed values of cloud asymmetry parameter, $g_{c}$, for the standard ISCCP-D2 cloud liquid droplet and ice crystal distributions in the ultraviolet (UV)-visible and near-infrared (IR) ranges of wavelength.

\begin{tabular}{lll}
\hline & liquid & ice \\
\hline UV-visible & 0.85 & 0.78 \\
Near-IR & 0.82 & 0.80 \\
\hline
\end{tabular}

The model uses cloud cover, $A_{c i}$, for each cloud type provided by ISCCP-D2 data set. Cloud cover fractions for low, mid, and high clouds are calculated from the sum of cover fractions for independent ISCCP-D2 cloud types, whereas the total cloud cover fraction, $A_{c}$, is calculated from the sum of fractions for low, middle and high clouds

$A_{c}=\sum_{i} A_{c i}$

Our computed global mean $A_{c}$ averaged over the study period $1984-1997$, is equal to $66.8 \%$ compared to $67.5 \%$ given by Rossow and Schiffer (1999) for the period June 1983June 1994. Note that the ISCCP-D2 cloud cover is higher than corresponding previous ISCCP-C 2 data by up to $25 \%$, especially over polar regions, and is in better agreement with surface observations (Hatzianastassiou et al., 2001).

The ISCCP-D2 provides cloud scattering optical depth $\tau_{c}^{s}$ only for the visible wavelength of $\lambda=0.6 \mu \mathrm{m}$ and at the infrared wavelength of $11 \mu \mathrm{m}$ (through a conversion, cf. Rossow et al., 1996). For the computation of the cloud SW transmissivity and reflectivity in both the UV-visible and near-IR, the model also requires cloud absorption optical depth, $\tau_{c}^{a}$, which is relevant to the near-IR solar radiation, but also $\tau_{c}^{s}$ data in the near-IR. The $\tau_{c}^{s}$ (near-IR) and $\tau_{c}^{a}$ (nearIR) values were derived from the ratios $\tau_{c}^{s}$ (near-IR) $/ \tau_{c}^{s}(\mathrm{UV}-$ visible) and $\tau_{c}^{a}$ (near-IR) $/ \tau_{c}^{s}(\mathrm{UV}$-visible) that resulted either from Mie computations code using the standard ISCCP liquid droplet spectrum, with a specific gamma distribution function having an effective radius, $r_{e}$, of $10 \mu \mathrm{m}$, and an effective variance of $0.15 \mu \mathrm{m}$ (Rossow et al., 1996) or from existing parameterizations (Slingo, 1989; Ebert and Curry, 1992) for ISCCP-D2 liquid and ice clouds. The standard ISCCP-D2 ice cloud model assumes a random fractal crystal shape and a 2-power law size distribution from 20 to $50 \mu \mathrm{m}$, with an effective radius of $30 \mu \mathrm{m}$ and an effective variance of $0.1 \mu \mathrm{m}$. Finally, values of $\tau_{c}^{a}$ (near-IR) $=0.08 \tau_{c}^{s}$ (UV-visible) and $\tau_{c}^{a}$ (near-IR) $=0.03 \tau_{c}^{s}(\mathrm{UV}$-visible) were used in the model for the liquid and ice clouds, respectively.

For the computation of cloud reflectivity and transmissivity, the model needs values for the cloud asymmetry parameter, $g_{c}$, which are not provided by ISCCP. In previous versions of the model (Vardavas and Koutoulaki, 1995; Hatzianastassiou and Vardavas, 1999, 2001) $g_{c}$ was set equal to 0.85 for the UV-visible range and 0.8 for the near-IR, based on the wavelength variation of $g_{c}$ given by Stephens (1979), for all clouds and without any discrimination between liquid and ice clouds. Nevertheless, liquid and ice clouds have a different $g_{c}$ spectral dependence (Liou, 2002). This was taken into account in our model by computing values for $g_{c}$ separately for liquid and ice clouds, for both UV-visible and near-IR range of wavelengths. The computation was based on existing parameterizations for liquid (Slingo, 1989) and ice clouds (Ebert and Curry, 1992) by using values of effective radius equal to $10 \mu \mathrm{m}$ and $30 \mu \mathrm{m}$ for the ISCCP-D2 standard liquid cloud droplets and ice crystals, respectively. The computed values are given in Table 1.

\subsection{Rayleigh scattering and surface reflection}

The Rayleigh scattering, due to air molecules, is considered in the model in the same way as in Vardavas and Koutoulaki (1995). The surface reflection is computed with the model at each pixel for each month of the period 19841997, as explained in Sect. 2 (Eq. 16) by considering four types of surface: land, ocean, snow, and ice (frozen ocean). Information on spatial and temporal variation of the fractional coverage of Earth surface by each type, was taken from ISCCP-D2 (see Sect. 2).

\subsection{Aerosol particles}

The aerosol particles perturb the radiation field sufficiently, especially that of SW radiation, to warrant their consideration in the estimation of the SW radiation budget. In this study, the radiative effect of aerosols at TOA, within the atmosphere, and at surface, is computed by the model using a modified two-stream approximation allowing for scattering and absorption in the UV-visible and near-IR ranges of wavelength. The model requires aerosol optical properties, namely aerosol optical thickness (AOT), single scattering albedo $\left(\omega_{a e r}\right)$, and asymmetry parameter $\left(g_{a e r}\right)$. The treatment of aerosols by the modified two-stream approximation allows for the marked forward-to-backward asymmetry of the phase function (Sagan and Pollack 1967; Irvirne 1968). Thus, the model allows for the strong forward scattering peak in the phase function for scattering by aerosols with values of the aerosol asymmetry parameter ranging from about 0.6 up to 0.85 . The AOT, $\omega_{a e r}$ and $g_{a e r}$ data were derived from GADS (Koepke et al., 1997) which is an improvement of the previous global aerosol climatology by D'Almeida et al. (1991). In GADS, aerosols are described as internal plus external mixtures of 10 main aerosol components, which are representative for the atmosphere and characterised through their size-distribution and refractive index, depending on wavelength. Data of AOT, $\omega_{a e r}$, and $g_{a e r}$, are provided by GADS at 61 wavelengths from 0.25 to $40 \mu \mathrm{m}, 27$ of which lie in the SW range, and for 8 values of relative humidity $(0,50$, $70,80,90,95,98$, and 99\%). Given the strong dependence 
of aerosol optical properties on ambient relative humidity, the original GADS properties were then computed in a realistic way, for actual relative humidity values for the aerosol layer, as explained in detail by Hatzianastassiou et al. (2004). The computed monthly mean AOT values vary at the pixel level up to about 0.5 , while the aerosol single scattering albedo ranges from 0.65 to 1 . Subsequently, the computed values of aerosol optical properties were averaged into the UV-visible and near-IR ranges, weighted by the spectral distribution of the incoming solar flux (Thakaekara and Drummond, 1971). A complete description of the treatment of aerosols in the model, as well as of GADS aerosol data, can be found in the work by Hatzianastassiou et al. (2004).

3.6 Cloud-top pressure, cloud physical thickness and surface pressure

Consideration of cloud-top pressure, $p_{c}$, and physical thickness, $d p_{c}$, in the model is important for the $\mathrm{SW}$ radiation budget at TOA, since they both determine the atmospheric layer where water vapour absorption is replaced by cloud scattering and absorption. Values of $p_{c}$ were taken from ISCCP-D2 for low, mid, and high-level clouds. The ISCCP-D2 does not provide $d p_{c}$ data, so these were estimated from Peng et al. (1982) for the Northern Hemisphere, as explained in the work by Hatzianastassiou and Vardavas (1999), while $d p_{c}$ values for Southern Hemisphere were estimated in the way described by Hatzianastassiou and Vardavas (2001), by combining the values from Peng et al. and those derived from Liou (1992). A complete topography scheme is included in the model, which uses surface pressure, $p_{s}$, data taken either from NCEP/NCAR or from ECMWF Global Reanalysis Projects gridded in $2.5^{\circ}$ by $2.5^{\circ}$ pixels for each month of the period 1984-1997. Consideration of topography is important for regions with high altitudes, such as the Tibetan plateau, Antarctica, Rocky mountains or the Andes mountains, for the correct computation of the layer and total atmospheric amounts of the gases considered in the study, as well as the correct extent of Rayleigh scattering layer and the appropriate computation of the mean humidity of aerosol layer.

\subsection{The ERBE data}

The ERBE with its three satellites, provides the most accurate and best calibrated long-term data for the radiation budget of the Earth. The 5-year (1984-1989) mean monthly $2.5^{\circ}$ equal-angle data that were used for the validation of our model results, were taken from the ERBE S4 high-accuracy monthly scanner data products, distributed by NASA Langley Research Center Atmospheric Sciences Data Center (ASDC). The ERBE S4 scanner data have been collected from scanning radiometers on the three ERBE satellites for combined satellite cases. The ERBE scanner instrument package contains three instruments used to measure $\mathrm{SW}(0.2-5 \mu \mathrm{m}), \mathrm{LW}(5-50 \mu \mathrm{m})$ and total $(0.2-200 \mu \mathrm{m})$ waveband radiation. Each detector scans the Earth from horizon to horizon, usually perpendicular to the satellite ground track. The ERBE instruments were launched on the NASA Earth Radiation Budget Satellite (ERBS), and the two National Oceanic and Atmospheric Administration (NOAA) Sun-synchronous polar orbiting satellites: NOAA9 and NOAA-10. The data used in this study (S4) include mean monthly values for the time periods during which the scanners were operational: November 1984-February 1990 for ERBS; February 1985-January 1987 for NOAA-9; and November 1986-May 1989 for NOAA-10. Other scanner and non-scanner ERBE data (e.g. S7, S8, S9, S10) are also available from Langley ASDC, but they have lower accuracy or low spatial resolution, so we decided to rely rather on ERBE-S4 data for our model validation, since they are considered to be of very good quality in terms of their spatial and temporal coverage and instrument accuracy. Besides, our model OSR fluxes have been further validated against longterm ERBE S-10N (WFOV NF Edition 2) non-scanner data covering the period from January 1985 to December 1997, in terms of comparison of long-term tendencies. In the future, it is planned to use also more recent and high-accuracy satellite OSR measurements, such as from CERES, ScaRab, MODIS, GERB, for studies covering more recent time periods.

\section{Model results}

\subsection{Seasonal and geographical distributions}

Figures 1a-d show the geographical distribution of the 14year average outgoing SW radiation (OSR) at TOA for the mid-seasonal months of January, April, July, and October. The OSR fluxes are determined by the incoming solar radiation (ISR) and the planetary albedo. More specifically, the latitudinal gradient is determined by the incoming solar flux, while the main longitudinal patterns are primarily due to features of global distribution of surface albedo and cloud cover. Thus, maximum OSR values reaching $350 \mathrm{Wm}^{-2}$ are found in polar regions during local summer, i.e. in January and July in the southern and northern hemispheres, respectively, when the incoming solar radiation reaches maximum values of $500 \mathrm{Wm}^{-2}$, especially during perihelion. The OSR decreases gradually from the summer towards the winter pole, in January and July, where it switches-off poleward of midto-high latitudes. The white areas in Fig. 1 correspond to missing model input data, especially those from ISCCP. Such a strong latitudinal OSR gradient is not found during spring and autumn (Figs. 1b, d). Large OSR fluxes are found over areas characterised by large surface albedo. For example, as large as 350 and $300 \mathrm{Wm}^{-2}$ are computed over Antarctica in January, and over Greenland and Arctic Ocean areas in July, respectively, i.e. over areas with surface albedo values larger than $80 \%$. Also, large OSR values are found over regions having large cloud amounts; thus, OSR values as high as 

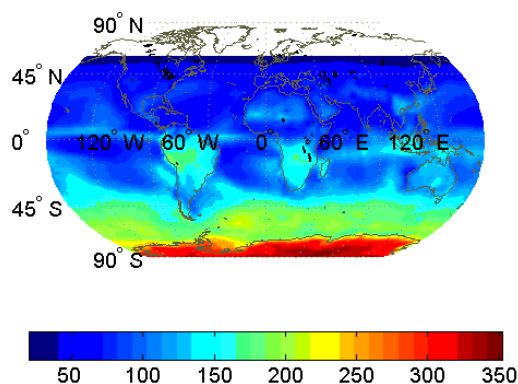

(a)
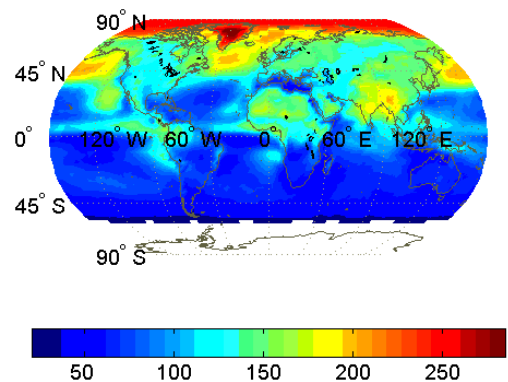
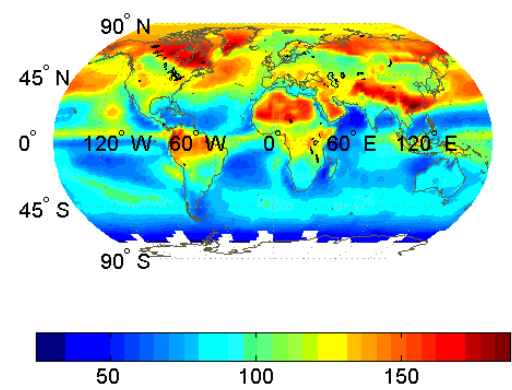

(b)

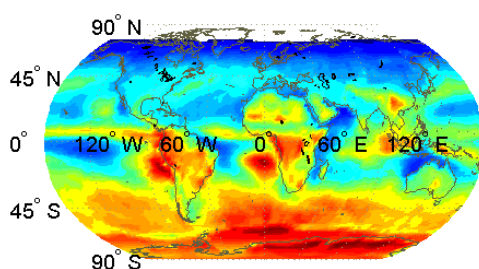

(c)

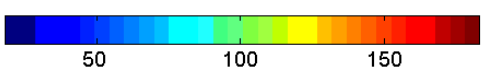

Fig. 1. Long-term (1984-1997) average global distribution of outgoing shortwave radiation (in $\mathrm{Wm}^{-2}$ ) at the top-of-atmosphere for the mid-seasonal months of (a) January, (b) April, (c) July, and (d) October.

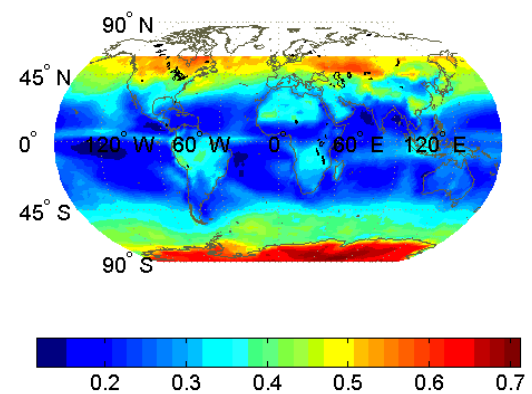

(a)
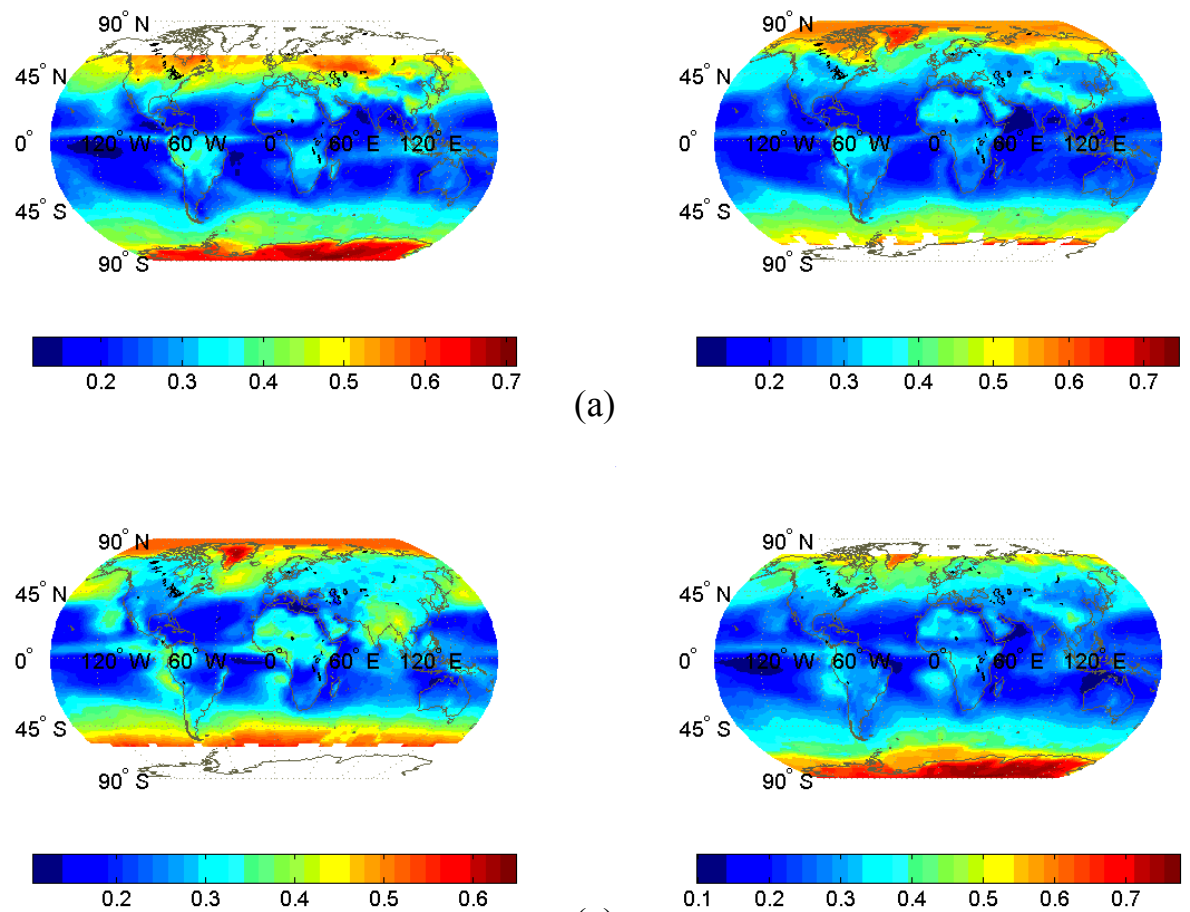

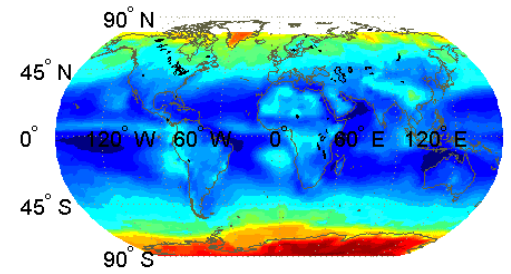

(c) (b)

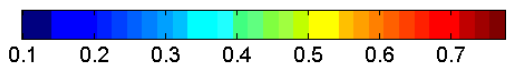

(d)

Fig. 2. Long-term (1984-1997) average global distribution of planetary albedo (in \%) at the top-of-atmosphere for the mid-seasonal months of (a) January, (b) April, (c) July, and (d) October. 

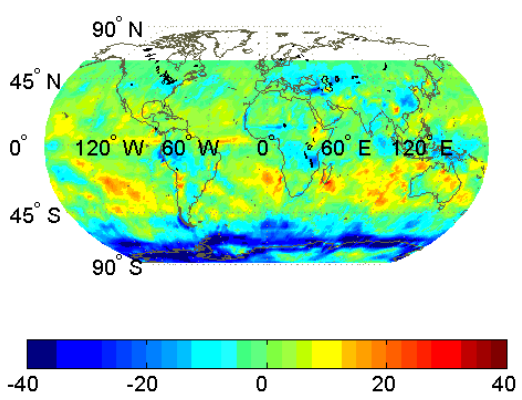

(a)
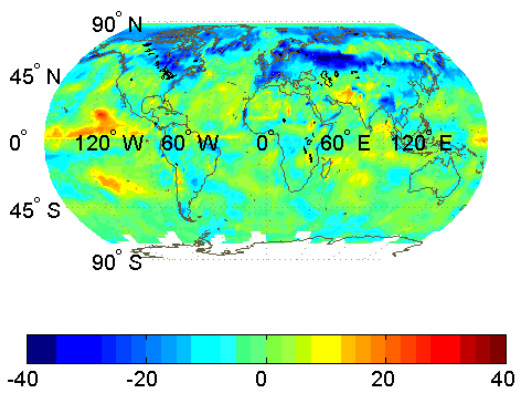

(b)

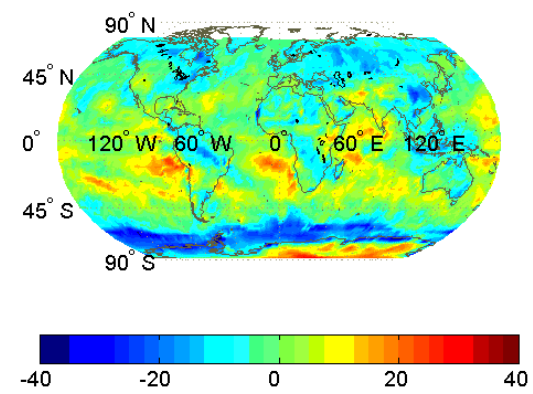

(d)

Fig. 3. Absolute differences (in $\mathrm{Wm}^{-2}$ ) between the 5-year (1985-1989) average model-computed and Earth Radiation Budget Experiment (ERBE) all-sky outgoing shortwave radiative fluxes at the top-of-atmosphere for the mid-seasonal months of (a) January, (b) April, (c) July, and (d) October.

$220 \mathrm{Wm}^{-2}$ are found over the storm track zone of the Southern Hemisphere, around $60^{\circ} \mathrm{S}$, in January, whereas values between $130-200 \mathrm{Wm}^{-2}$ are computed in October. A corresponding feature, with OSR equal to up to $200 \mathrm{Wm}^{-2}$ in April and July, appears over northern Pacific oceanic areas with large cloud amounts. Note also the relatively large OSR values over south-eastern Asia in July, where a large cloud cover exists, associated with monsoons. Relatively large OSR fluxes also appear along the inter-tropical convergence zone (ITCZ). Apart from lowest OSR values in the winter hemisphere, low values are found over regions with low surface albedo, which are at the same time characterised by warm subsidence associated with anticyclonic conditions, such as oceanic areas in low latitudes of the summer hemisphere. When high-pressure systems are established over regions of larger surface albedo during summer (e.g. north Africa) larger OSR values (up to $\approx 150 \mathrm{Wm}^{-2}$ ) are found. More generally, OSR fluxes show minima over subsidence regions with small cloud amounts, and over polar areas of the winter hemisphere, against maxima over cloudy areas and polar areas of the summer hemisphere.

The planetary albedo, $R_{p}$, given in Figs. 2a-d, shows interesting geographic structure. It is highest over polar and high-altitude areas, which are characterised by large solar zenith angle and surface albedo values, throughout the year. There, $R_{p}$ values are as high as $75 \%$. Note the gradual de- crease of $R_{p}$ over mid-to-high oceanic areas, e.g. the Southern Hemisphere windy zone, due to Fresnel reflection. Secondary maxima of planetary albedo values occur over cloudy tropical and sub-tropical areas and over highly reflecting surfaces such as the Sahara. The lowest $R_{p}$ values are found over tropical and sub-tropical oceanic areas (with surface albedo lower than 10\%), especially those with small cloudiness. When clouds are present above such oceanic areas, e.g. marine stratus clouds off the coasts of western United States, South Africa and South America, then $R_{p}$ increases up to $40 \%$. The systematically large values of $R_{p}$ over midto-high latitude and especially polar regions, indicates the importance of these regions in terms of their sensitivity to possible climatic changes (IPCC, 2001).

The mean monthly $2.5^{\circ}$ by $2.5^{\circ}$ OSR model results were validated against corresponding ERBE-S4 quality scanner data, available for the 5-year period from 1985 to 1989 , as explained in Sect. 3.7. The absolute differences (in $\mathrm{Wm}^{-2}$ ) between the averaged model results over the 5year period, and the corresponding ERBE data, at the pixel level, are found to be mostly within $\pm 10 \mathrm{Wm}^{-2}$, and even $\pm 5 \mathrm{Wm}^{-2}$ over extended regions (Fig. 3), i.e. within or close to the uncertainty of the ERBE scanner data. However, there are some areas where model-ERBE differences reach $30-40 \mathrm{Wm}^{-2}$. Specifically, the model underestimates OSR with respect to ERBE, by up to $40 \mathrm{Wm}^{-2}$ in October 


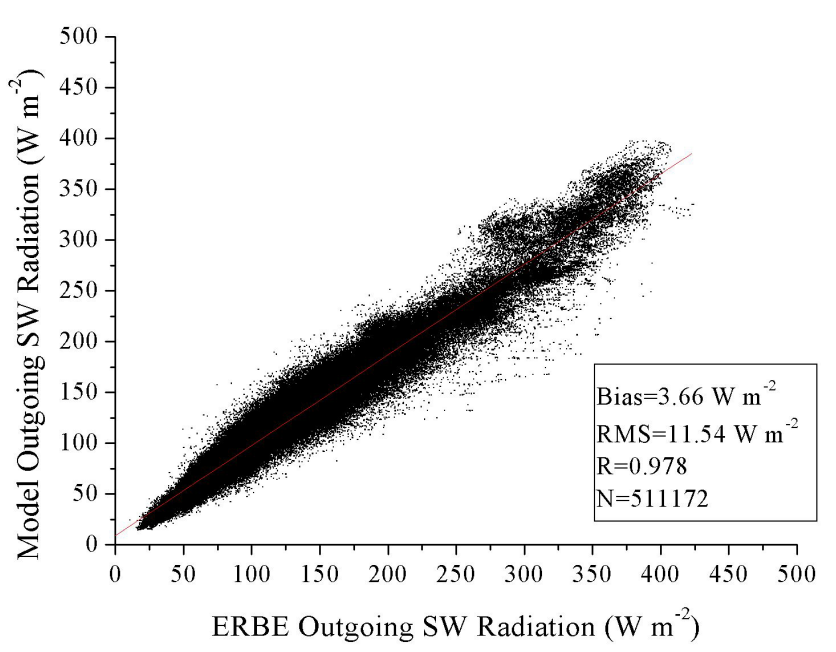

Fig. 4. Scatter plot comparison between model-computed and Earth Radiation Budget Experiment (ERBE) pixel data of monthly average outgoing shortwave radiation at the top-of-atmosphere, over the 5-year (1985-1989) period.

and January, along the coastal Antarctic region, as well as over the windy zone of Southern Hemisphere, especially its western part. It also underestimates OSR over Greenland in July, by up to $40 \mathrm{Wm}^{-2}$, and over the Arctic Ocean in April and July, by $10-30 \mathrm{Wm}^{-2}$. The most probable sources for the above discrepancies between model and ERBE, are the ISCCP-D2 cloud cover, $A_{c}$, data used by the model and surface albedo, $R_{g}$. The surface albedo below $1 \mathrm{~km}$ elevation is reduced by conditions such as blue ice in the ablation zone or snow with larger grain size, which change considerably on the slope near the coast (Watanabe, 1978). Besides, there are generally many difficulties to detect clouds from both satellites (Rossow and Schiffer, 1999) and surface (Schweiger et al, 1999), especially over highly reflecting surfaces, such as snow- or ice-covered polar regions. Comparisons made between ISCCP-D2 cloud cover and other corresponding satellite-based (e.g. Meteor-I,II; Nimbus-7) Reanalysis (ERA-15, ECMWF) and ground-based (Hahn et al., 1995) data, indicate that although the ISCCP-D2 $A_{c}$ data were greatly improved with respect to the previous ISCCP$\mathrm{C} 2$ cloud products, they still seem to underestimate $A_{c}$ by up to $20 \%$ over the Arctic from spring through the summer, e.g. April and July, Fig. 3, as well as over Antarctica by up to $40 \%$ during autumn and winter, e.g. October and January, Fig. 3, (see Hatzianastassiou et al., 2001). Indeed, based on an assessment of the sensitivity of model OSR fluxes to various key physical parameters (i.e. $A_{c}, \tau_{c}^{s}, \tau_{c}^{a}, R_{g}, W_{\mathrm{H} 2 \mathrm{O}}, W_{\mathrm{O} 3}$ ), which is given in Sect. 4.7, the cloud parameters: $A_{c}, \tau_{c}^{s}$, $\tau_{c}^{a}$, and surface albedo, were found to modify greatly OSR fluxes over the areas of model - ERBE discrepancies. An increase in total $A_{c}$ by $30 \%$ (equally distributed to low, middle, and high clouds), modified OSR over the oceanic areas of model underestimation, by up to $15 \mathrm{Wm}^{-2}$, while an in- crease of $\tau_{c}^{s}$ and $\tau_{c}^{a}$ by $10 \%$, increased OSR by up to 8 and $3 \mathrm{Wm}^{-2}$, respectively. Thus, overall, cloud parameters were found to be able to account for up to about $20-30 \mathrm{Wm}^{-2}$ of the total model OSR underestimation. Also, an increase in $R_{g}$ by $10 \%$, increased OSR by up to $30 \mathrm{Wm}^{-2}$. In contrast, the sensitivity of OSR to the rest of the parameters, was shown to be very small $\left(\leq 3 \mathrm{Wm}^{-2}\right)$. The role of $A_{c}$ data for the model OSR underestimation is further supported by the fact that the agreement with ERBE seems to improve significantly during local autumn and winter, i.e. when ISCCP-D2 cloud products are assumed to be better. On the other hand, initially, the model was found to overestimate OSR by up to about $40 \mathrm{Wm}^{-2}$ over mountainous areas, such as Himalayas, Tibetan plateau, Mongolia, plateau of Antarctica, Andes, as well as Rocky mountains. Nevertheless, the model results shown here are significantly improved in terms of agreement with ERBE, by applying the surface albedo correction, i.e. $R_{g}$ reduction, discussed in Sect. 2. A model OSR overestimation by up to $20 \mathrm{Wm}^{-2}$ exists off the western coast of northern America in July, and off the western coast of southern America and south Africa in July, i.e. over areas with significant cloudiness.

Figure 4 shows the scatter plot comparison between model-computed and ERBE-S4 scanner data at the pixel level and monthly mean term, for the 5-year period from January 1985 through December 1989. The total 511172 pixel data comparison between model and ERBE OSR fluxes, reveals an encouraging agreement. The scatter plot shows a bias (i.e. the difference between the averaged model and ERBE OSR values over the total 511172 pixel level matched data pairs) equal to $3.7 \mathrm{Wm}^{-2}$, indicating an overall model overestimation of OSR fluxes, with a small scatter (rms difference equal to $11.54 \mathrm{Wm}^{-2}$ ) and a high correlation coefficient, equal to $97.8 \%$.

\subsection{Time series}

Figures 5a-b show the time series of the mean monthly hemispheric and global average components of TOA SW radiation budget for the entire 168-month period 1984-1997. The incoming SW radiation (ISR) at TOA shows a strong seasonal cycle for the hemispheric averages. Southern Hemisphere, $\mathrm{SH}$, has a significantly larger amplitude (about $300 \mathrm{Wm}^{-2}$ ) than Northern Hemisphere, NH (about $250 \mathrm{Wm}^{-2}$ ) related to the fact that the Earth-Sun distance is minimum during December-January (SH summer) and becomes maximum during June-July, i.e. at perihelion and aphelion, respectively, because of the eccentricity of the Earth's orbit. Therefore, the summer-maximum of incoming SW radiation for SH reaches about $480 \mathrm{Wm}^{-2}$ against $460 \mathrm{Wm}^{-2}$ for $\mathrm{NH}$. The hemispheric ISR averages balance each other so to produce a monthly mean global average incoming SW flux that shows a small seasonal variability $\left(\approx 20 \mathrm{Wm}^{-2}\right)$ with maxima in January and minima in July. The interannual tendency is found to be very small $\left(0.1 \mathrm{Wm}^{-2}\right.$ over 
14 years) indicating a very slight decrease. An increasing trend of total solar irradiance between 1986 and 1996 was derived by Willson (1997), while Frölich and Lean (1998) did not find any significant trend (for a discussion, see IPCC, 2001). Note that the linear regression of annual mean Sunspot numbers (National Geophysical Data Center, NGDC, http://www.ngdc.noaa.gov) involves also a slightly decreasing trend. In any case, if true, our slightly decreasing trend in incoming solar radiation at TOA, represents a radiative forcing of $0.017 \mathrm{Wm}^{-2}$ over the 14 -year period from 1984 through 1997.

Time series of OSR (Fig. 5a) show some similar features with ISR. Thus, OSR has maxima of about $150 \mathrm{Wm}^{-2}$ in December for SH, and minima of about $70 \mathrm{Wm}^{-2}$ in June, which imply an annual amplitude of about $80 \mathrm{Wm}^{-2}$. The corresponding minimum and maximum OSR values for $\mathrm{NH}$ are equal to about 130 and $70 \mathrm{Wm}^{-2}$, respectively, around June and December, with an annual amplitude of about $60 \mathrm{Wm}^{-2}$, i.e. smaller by $20 \mathrm{Wm}^{-2}$ than for SH. As a result of the balance between the two hemispheres, the computed monthly mean global average OSR exhibits a time evolution with primary and secondary maxima and minima. Thus, global OSR has primary maxima of about $115 \mathrm{Wm}^{-2}$ in December, and secondary maxima of about $100-105 \mathrm{Wm}^{-2}$ in June, whereas it has primary and secondary minima equal to about 95 and $100 \mathrm{Wm}^{-2}$ in September and March, respectively, i.e. during the transitional seasons. The annual range of OSR values is roughly equal to $20 \mathrm{Wm}^{-2}$. The applied linear regression to global OSR 14-year time series, shows a decreasing OSR trend equal to $2.3 \mathrm{Wm}^{-2}$ over the time period 1984-1997. This long-term decrease cannot be attributed to the incoming solar radiation at TOA, since the later has a very small trend of $0.1 \mathrm{Wm}^{-2}$, so it must be due to internal physical parameters of the Earth-atmosphere system, as we will see later on. The decrease of OSR by $2.3 \mathrm{Wm}^{-2}$ over the 14-year period 1984-1997, is very important and needs to be further examined in detail. The decreasing trend in global OSR can be also seen in Fig. 5b, where the mean global planetary albedo, $R_{p}$, is found to have decreased by $0.6 \%$ from January 1984 through December 1997. The mean global $R_{p}$ varies between about 0.285 and 0.33 .

Our analysis shows that the decrease in the mean global values of OSR, and $R_{p}$, arises primarily in the Northern Hemisphere, especially in the tropical and sub-tropical regions (see Sect. 4.3). More specifically, the linear regression analysis in time series of monthly mean $10^{\circ}$ zonally averaged OSR fluxes, indicates a negative slope (decreasing OSR) in latitude zones between $20^{\circ} \mathrm{S}$ and $40^{\circ} \mathrm{N}$, which is even stronger between $20^{\circ} \mathrm{S}$ and $20^{\circ} \mathrm{N}$. Such a decreasing OSR trend between $20^{\circ} \mathrm{S}$ and $20^{\circ} \mathrm{N}$ over the study period, was also reported recently by Wielicki et al. (2002), from satellite observations (Nimbus-7, ERBS, ScaRab, CERES). Our deterministic model is able to reproduce here the decreasing OSR trend, as suggested by satellites, over the 14year period (1984-1997), in contrast to several climate mod-

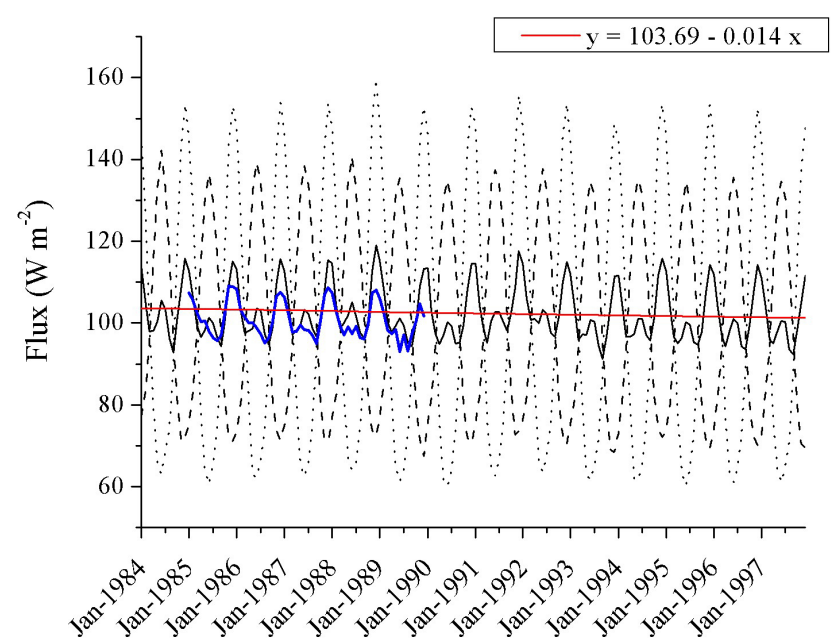

(a)

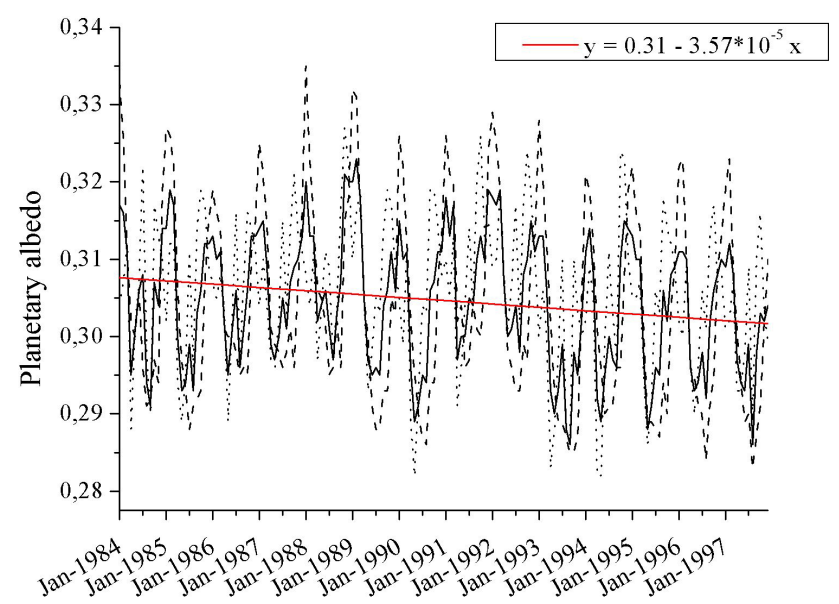

(b)

Fig. 5. Time series of monthly average top-of-atmosphere: (a) outgoing shortwave radiation (in $\mathrm{Wm}^{-2}$ ) and (b) planetary albedo (in \%), for the 14-year (1984-1997) period for the Globe (solid lines), Northern Hemisphere (dashed lines), and Southern Hemisphere (dotted lines). The linear regression for the time series of the Globe is also shown. The corresponding time series of outgoing shortwave radiation (in $\mathrm{Wm}^{-2}$ ) from 5-year (1985-1989) ERBE$\mathrm{S} 4$ scanner data (blue line) is also given in Fig. $5 \mathrm{a}$.

els, which fail to predict this large observed variation in tropical energy budget, due to the fact that they lack either some internal physical process or some additional external forcing that is responsible for changes in TOA fluxes (Allan and Slingo, 2002). Wielicki et al. (2002) suggested that the changes in tropical radiation budget at TOA are caused by changes in tropical cloudiness. We have performed a detailed analysis to investigate the causes of the detected OSR decreasing trend. We computed the correlation coefficients between long-term tendencies of OSR and various physical parameters that determine OSR, on a monthly mean global 


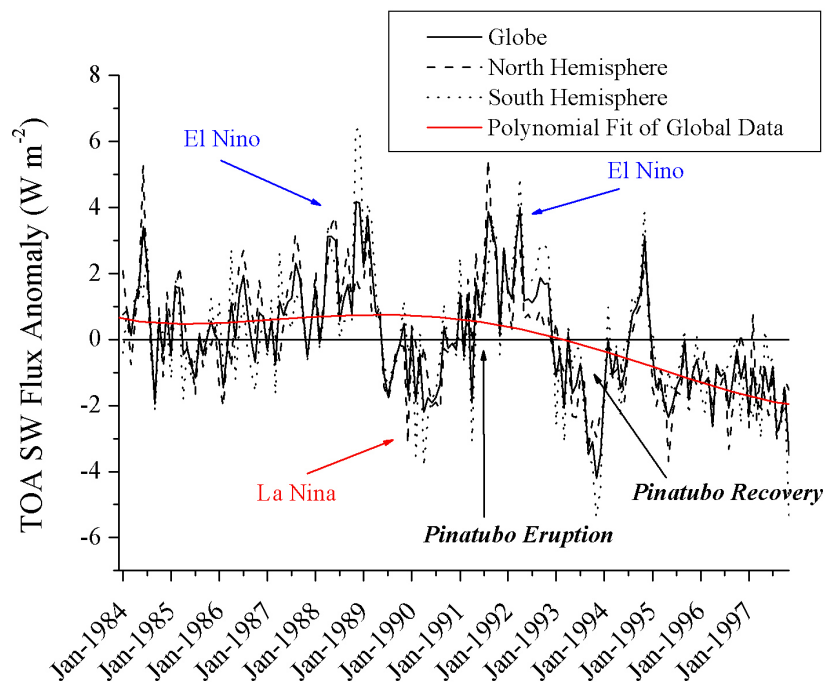

Fig. 6. Time-series of global and hemispherical averages of top of atmosphere outgoing shortwave radiation flux anomalies (in $\mathrm{Wm}^{-2}$ ) over the period 1984-1997 for the Globe (solid lines), Northern Hemisphere (dashed lines), and Southern Hemisphere (dotted lines). The 4th-order polynomial fit of the global data is also shown.

and hemispherical average basis. In our model, these parameters are: cloud (low, middle and high-level) cover, cloud absorption and scattering optical depths, surface albedo, total precipitable water, total column ozone concentration and incoming SW radiation at TOA. The results of our analysis have shown that cloud cover, especially the low-level one, and secondarily cloud optical depth, have coefficients between 0.3 and 0.5 , against much smaller coefficients for the rest of parameters. This is very important in terms of the role of tropical low clouds for the SW radiation budget (Hartmann et al., 2001), but also for their radiative effects in the iris feedback (Fu et al., 2002). Thereafter, we have performed a more detailed analysis on $10^{\circ}$ latitude-zonal basis, which shows that correlation coefficients of $0.4-0.55$ between OSR and low-level cloudiness, exist only in zones between $40^{\circ} \mathrm{S}$ and $40^{\circ} \mathrm{N}$, while they gradually drop down to $0.1-0.3$ towards the poles. A more detailed study is in preparation, dealing with exclusively the analysis of OSR inter-annual trends and their causes.

Anomalies in mean global and hemispherical OSR fluxes have been determined from the 14-year model results, and are shown in Fig. 6. The global mean OSR anomaly shows great variations reaching values of $4 \mathrm{Wm}^{-2}$, above or below the 14-year mean value. During the 1991-1992 period, a large increase in the reflected OSR flux is found, which can be attributed to Mount-Pinatubo eruption in 1991. The induced rapid increase in OSR is followed by a recovery period. Note that the large positive OSR anomaly around 19911992, which is seen in Fig. 6 for the globe, can be more clearly seen in the $10^{\circ}$ zonally-averaged OSR anomalies, for

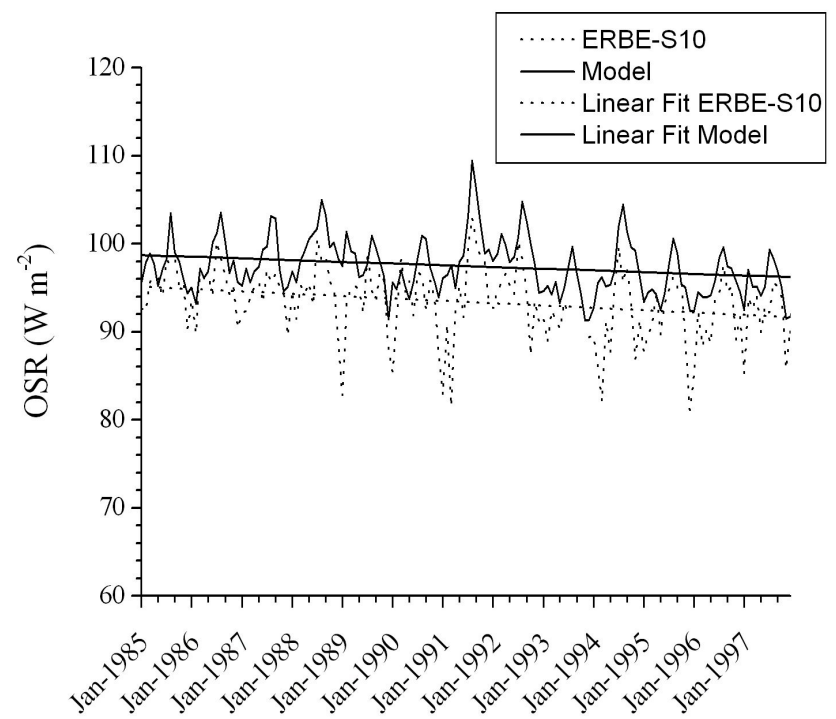

(a)

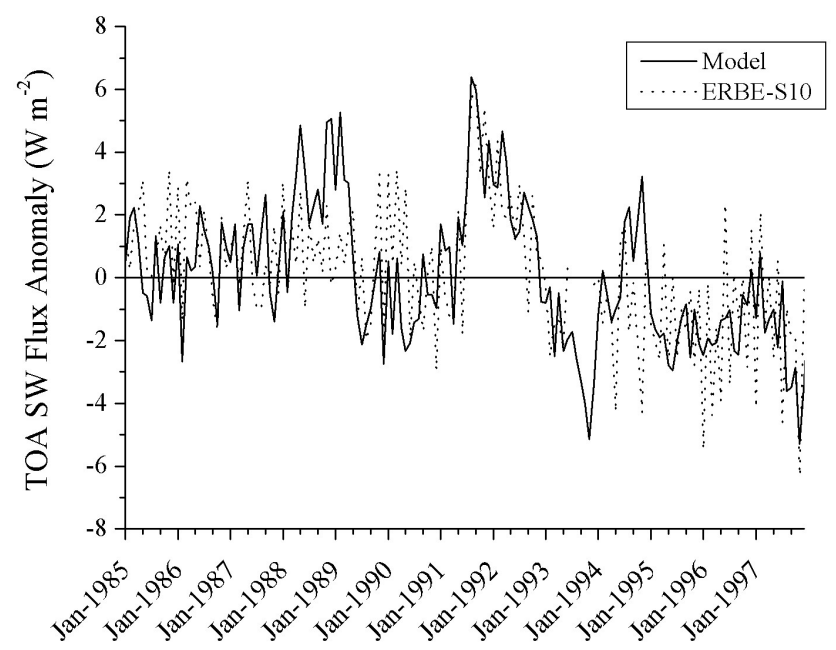

(b)

Fig. 7. Time series of monthly average top-of-atmosphere: (a) outgoing shortwave radiation (in $\mathrm{Wm}^{-2}$ ) and (b) outgoing shortwave radiation flux anomalies (in $\mathrm{Wm}^{-2}$ ), over the period (1985-1997) for the region $\left(30^{\circ} \mathrm{S}-30^{\circ} \mathrm{N}\right)$ from the model (solid lines) and the ERBE S-10N (WFOV NF Edition 2) non-scanner measurements (dotted lines). The corresponding linear regression for both time series, are also shown in (a).

the zones $20^{\circ} \mathrm{S}-20^{\circ} \mathrm{N}$, where it reaches values of $10 \mathrm{Wm}^{-2}$. Other interesting features can be also seen in Fig. 6, such as positive and negative OSR anomalies during El Niño and La Niña events, respectively. In Fig. 6 is also given the 4thorder polynomial fit to 14-year time series of global averages of OSR anomalies, which shows significant negative OSR anomalies (decreasing OSR), starting from year 1992, in agreement with Wielicki et al. (2002), who suggested a significant increase in tropical mean outgoing LW radiation 
at TOA (see also Hatzidimitriou et al., 2004), and an associated decrease in OSR, since 1992, based on satellite data. Our work indicates that the globally-averaged decreasing tendency in OSR (Fig. 6) is attributed to the tropical and subtropical regions, as well as to the mid latitudes, but to a lesser extent; an opposite increasing trend is found over sub-polar and polar areas $\left(60^{\circ}-90^{\circ} \mathrm{N}\right.$ and $\left.\mathrm{S}\right)$. The inter-annual decreasing trend in OSR is caused by cloudiness, as also suggested by Wielicki et al. (2002). According to the analysis of our model-computed SW radiation budget at TOA, there is an increase in the SW radiative heating over low and middle latitudes, and a decrease over high-latitude polar areas. If true, this might be very important for atmospheric dynamics, general circulation of the atmosphere and climate.

Of course, one can ask to what extent can one trust the variations found in the time series of global and hemispherical mean reflected solar radiation, since they are solely based on time series of model results computed using ISCCP data. The ISCCP data, however, are based on calibrated narrowband measurements from meteorological satellites whose orbits and calibrations vary during the period of interest (e.g. Klein and Hartmann, 1993). Although some of the most serious calibration changes have been adjusted for in the last ISCCP-D series data (Rossow and Schiffer, 1999), the question remains with regard to the reliability of the ISCCP longterm trends. On the other hand, it is interesting that the model computed OSR fluxes are in remarkable agreement with direct radiation satellite measurements from ERBE. Apart from the validation of the model OSR against quality ERBES4 scanner data (which however cover only the 5-year period 1985-1989), our model OSR has been further validated against long-term ERBE S-10N (WFOV NF Edition 2) nonscanner data covering the period from January 1985 to December 1997, and the comparison is given in Fig. 7. Our model OSR fluxes are found to be in very good agreement with those of ERBE S-10N, either in terms of OSR fluxes or their anomalies. Both model and ERBE S-10N OSR fluxes show a decreasing trend from 1985 through 1997, equal to about 2 and $2.5 \mathrm{Wm}^{-2}$ per decade, respectively, while the computed anomalies in both model and ERBE S-10N OSR fluxes are very similar. Nevertheless, note that the results of Fig. 7 refer to the tropical and sub-tropical regions $\left(30^{\circ} \mathrm{S}-\right.$ $30^{\circ} \mathrm{N}$ ) only, and not to the whole globe (as in Figs. 5 and 6). This was done for two reasons. First, ERBE S-10N does not provide data poleward of $60^{\circ} \mathrm{N}$ and $\mathrm{S}$, while there are missing data between $30^{\circ}$ and $60^{\circ} \mathrm{N}$ and S. Secondly, the global decreasing trend in OSR was found to be largely attributed to the tropical and sub-tropical regions.

4.3 Mean annual, hemispherical, and global TOA SW radiation budget components

Mean monthly $10^{\circ}$ latitude zonal fluxes and planetary albedo were computed by averaging first along $2.5^{\circ}$-width longitudinal circles, then along with latitude, by considering the

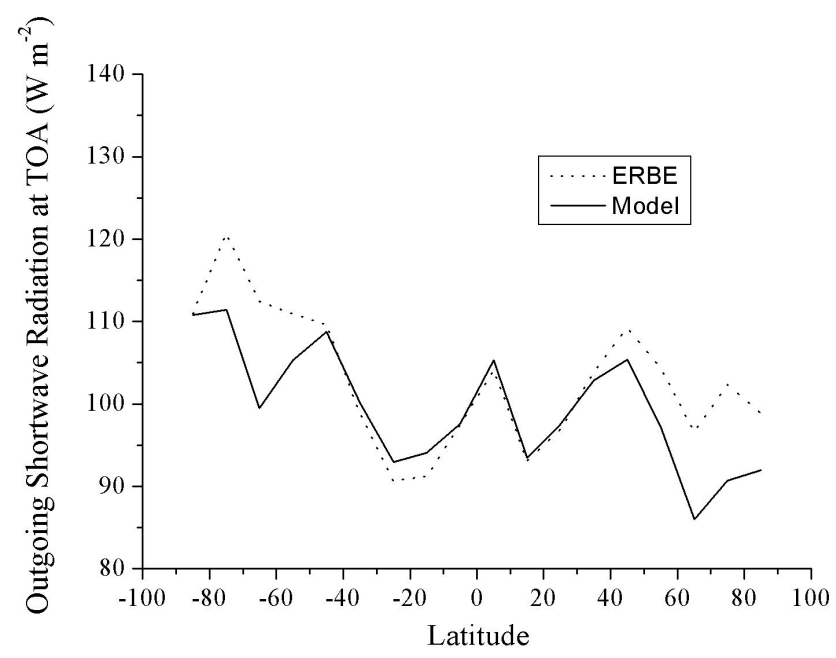

(a)

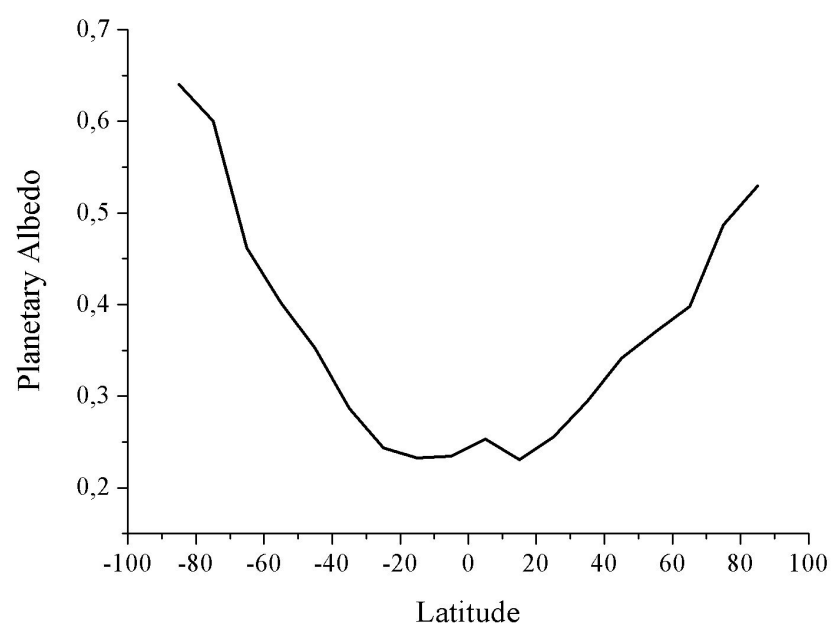

(b)

Fig. 8. Latitudinal variation of model computed mean annual: (a) outgoing shortwave radiation (in $\mathrm{Wm}^{-2}$ ) at the top-of-atmosphere, and (b) planetary albedo (in \%), for the period January 1984 through December 1997. In Fig. 8a, the corresponding outgoing shortwave radiation (in $\mathrm{Wm}^{-2}$ ) at the top-of-atmosphere from 5-year (19851989) ERBE-S4 scanner data (dotted line) is also shown.

fraction of surface area contained in each $2.5^{\circ}$ zone. Subsequently, annual mean quantities were computed by summing the corresponding monthly means for each $10^{\circ}$ latitudinal zone over the 12 months of the year. The latitudinal variation of mean annual TOA OSR flux, and planetary albedo, $R_{p}$, are given in Figs. 8a, b. The yearly averaged incoming SW radiation has maximum values of about $425 \mathrm{Wm}^{-2}$ along the equator, and drops rapidly to about $175 \mathrm{Wm}^{-2}$ towards the poles, due to the latitudinal variation of solar zenith angle. However, note that the equator-to-pole decrease of ISR is associated with a corresponding increase of ISR seasonal variability (not shown here). The reflected OSR flux 
Table 2. Model computed mean annual hemispherical (NH is Northern Hemisphere, SH is Southern Hemisphere) and global average: incoming shortwave radiation $\left(F_{\downarrow}\right)$, outgoing shortwave radiation $\left(F_{\uparrow}\right)$ and net incoming shortwave radiation $\left(F_{n e t, \downarrow}\right)$ at the top-of-atmosphere, and planetary albedo $\left(R_{p}\right)$, for the 14-year (1984-1997) period. The radiative fluxes are expressed in $\mathrm{Wm}^{-2}$, while the planetary albedo in $\%$.

\begin{tabular}{lcccc}
\hline & $F_{\downarrow}$ & $F_{\uparrow}$ & $F_{n e t, \downarrow}$ & $R_{p}$ \\
\hline NH & 341.7 & 100.6 & 241.1 & 29.45 \\
SH & 341.3 & 101.7 & 239.6 & 29.80 \\
Globe & 341.5 & 101.2 & 240.3 & 29.62 \\
\hline
\end{tabular}

(Fig. 8a) is maximum at the South pole $\left(\approx 111 \mathrm{Wm}^{-2}\right)$, while it has secondary maxima of about $108 \mathrm{Wm}^{-2}$ near $50^{\circ} \mathrm{N}$ and $\mathrm{S}$, and another maximum of about $105 \mathrm{Wm}^{-2}$ near the equator. Overall, it varies with latitude between about 85 and $110 \mathrm{Wm}^{-2}$. The latitudinal variation of OSR depends on scattering and absorption processes and on atmospheric conditions such as the variation in amounts and types of clouds with latitude. In the tropics, about $25 \%$ of the incoming mean annual solar radiation is scattered back to space ( $R_{p} \approx 0.25$, Fig. $8 \mathrm{~b}$ ). The planetary albedo increases from the equator to the poles, with a small minimum between $10^{\circ}$ and $20^{\circ} \mathrm{N}$ and $\mathrm{S}$, reaching values of $65 \%$ and $50 \%$ at the south and north poles, respectively. The general equator-to-pole increase in $R_{p}$ is caused by increasing surface albedo values, associated with larger land-to-sea fractions and snow and icecovered areas, increasing solar zenith angle, and high cloud amounts. The secondary $R_{p}$ minimum near the equator is due to large cloud amounts along the ITCZ.

Hemispherical and global mean values were computed as explained in Hatzianastassiou and Vardavas (1999) and are given in Figs. 9a, b. The mean hemispherical ISR fluxes have opposite seasonality, with values ranging between about 200 and $475 \mathrm{Wm}^{-2}$, resulting in a mean global ISR ranging from 330 to $352 \mathrm{Wm}^{-2}$ throughout the year. The seasonal range of southern ISR is slightly larger than the northern one. It is the same with the mean hemispherical OSR (Fig. 9a), which ranges from about 60 to roughly $140 \mathrm{Wm}^{-2}$ for the Northern Hemisphere, and between 55 and $155 \mathrm{Wm}^{-2}$ in Southern. The mean global OSR has a very small seasonal variability of about $15 \mathrm{Wm}^{-2}$, i.e. between 95 and $110 \mathrm{Wm}^{-2}$, with a minimum in late summer - early autumn, in excellent agreement with satellite measurements (Duvel et al., 2001). The mean hemispherical planetary albedo does not show great seasonality; it varies between $27.5 \%$ (minimum value in October) and $29.9 \%$ (maximum value in June) for Northern Hemisphere, and between $26.6 \%$ (minimum in June) and $31.3 \%$ (maximum in December) for Southern Hemisphere. The global mean planetary albedo ranges from $28 \%$ in September to $30.5 \%$ in December, showing a seasonal variability equal to about $2.5 \%$.

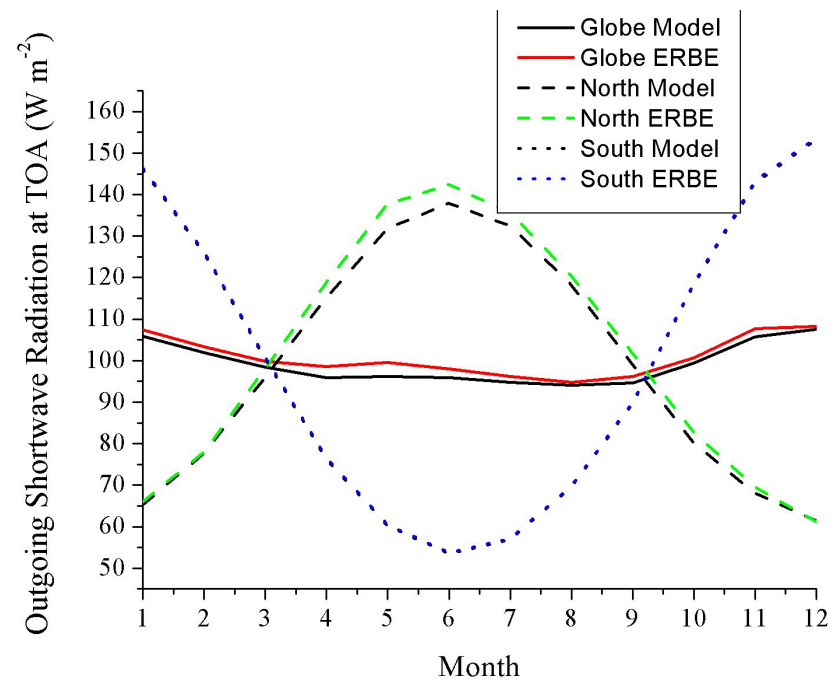

(a)

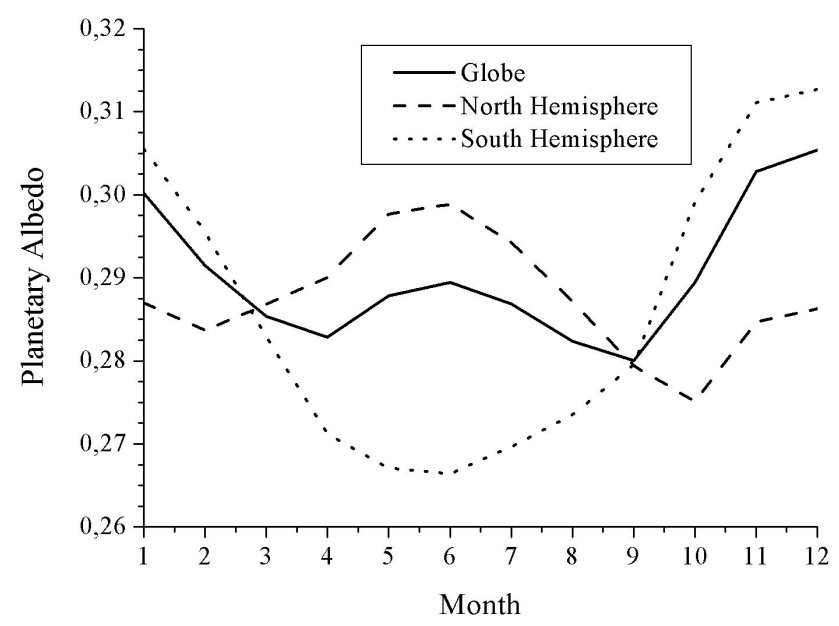

(b)

Fig. 9. Seasonal variation of hemispherical and global averages of model computed: (a) outgoing shortwave radiation (in $\mathrm{Wm}^{-2}$ ) at the top-of-atmosphere, and (b) planetary albedo (in \%), for the period January 1984 through December 1997. The corresponding outgoing shortwave radiation (in $\mathrm{Wm}^{-2}$ ) at the top-of-atmosphere from 5-year (1985-1989) ERBE-S4 scanner data, are also plotted in Fig. 9a.

The mean annual hemispherical and global average values over the 14-year period from 1984 to 1997 , for the incoming, outgoing, net incoming (i.e. absorbed) SW radiation at TOA, and planetary albedo, are given in Table 2 , while in Table 3, our computed OSR and $R_{p}$ values are also compared against ERBE data and other published values. On a 14-year basis (1984-1997), the Earth is found to reflect back-to-space $101.2 \mathrm{Wm}^{-2}$ from the global mean received $341.5 \mathrm{Wm}^{-2}$, resulting in a long-term planetary albedo equal to $29.6 \%$. The inter-hemispherical differences are equal to $0.34 \mathrm{Wm}^{-2}$ for ISR, $1.1 \mathrm{Wm}^{-2}$ for OSR, $1.43 \mathrm{Wm}^{-2}$ for the 
Table 3. Model mean annual hemispherical and global averages of outgoing shortwave radiation at the top-of-atmosphere $\left(F_{\uparrow}\right)$, and planetary albedo $\left(R_{p}\right)$, as computed in this study, compared with values from others. NH is Northern Hemisphere, SH is Southern Hemisphere. The radiative fluxes are expressed in $\mathrm{Wm}^{-2}$, while the planetary albedo in \%.

\begin{tabular}{|c|c|c|c|c|c|c|}
\hline \multirow[t]{2}{*}{ Study } & \multicolumn{3}{|c|}{$F_{\uparrow}$} & \multicolumn{3}{|c|}{$R_{p}$} \\
\hline & NH & $\mathrm{SH}$ & Globe & $\mathrm{NH}$ & $\mathrm{SH}^{\circ}$ & Globe \\
\hline Present Study (1984-1997) & 100.6 & 101.7 & 101.2 & 29.45 & 29.80 & 29.62 \\
\hline Present Study (1985-1989) & 101.3 & 102.4 & 101.8 & 29.65 & 29.99 & 29.82 \\
\hline ERBE (1985-1989) & 101.0 & 100.8 & 100.9 & 30.10 & 29.10 & 29.6 \\
\hline Hatzianastassiou and Vardavas (2001) & & 103.0 & & & 29.6 & \\
\hline Hatzianastassiou and Vardavas (1999) & 100.8 & & & 29.6 & & \\
\hline NCEP Reanalysis (1982-1994) & & & 115.7 & & & 33.87 \\
\hline ECMWF Reanalysis (1985-1993) & & & 103.7 & & & 30.36 \\
\hline NASA Reanalysis (1981-1992) & & & 94.7 & & & 27.72 \\
\hline Yang et al. (1999) & & & 115.3 & & & \\
\hline Wild et al. (1998-ECHAM4) & & & 105.0 & & & 30.7 \\
\hline Wild et al. (1998-ECHAM3) & & & 107.0 & & & 31.29 \\
\hline Li et al. (1997) & & & $94.8-111.5$ & & & $27.6-32.6$ \\
\hline Chen and Roeckner (1996) & & & 106.4 & & & 31.0 \\
\hline Rossow and Zhang (1995) & & & 111.5 & & & 32.6 \\
\hline Vardavas and Koutoulaki (1995) & & & & 30.6 & & \\
\hline Kiehl et al. (1994) & & & 96.6 & & & 28 \\
\hline Hartmann (1993) & & & & & 29.20 & \\
\hline Liou (1992) & & & & 30.0 & & \\
\hline Ardanuy et al. (1991) & & 111.0 & & & & \\
\hline Rossow and Lacis (1990) & & & & & 33.0 & \\
\hline Smith and Smith (1987) & & & & & 29.0 & \\
\hline Stephens et al. (1981) & & & & 30.0 & 29.7 & 29.85 \\
\hline Peng et al. (1982) & & & & 31.0 & & \\
\hline Ohring and Addler (1978) & & & & 31.3 & & \\
\hline Hoyt (1976) & & & & 32.1 & & \\
\hline Sasamori et al. (1972) & & & & & 34.7 & \\
\hline Bridgman (1969) & & & & & 40.0 & \\
\hline London (1957) & & & & 35.2 & & \\
\hline
\end{tabular}

net incoming SW radiation at TOA, and $0.35 \%$ for $R_{p}$, implying slightly larger northern than southern hemispherical values for the net incoming SW radiation at TOA. In Table 3 are also given the averages of model computed OSR and $R_{p}$ values over the 5-year 1985-1989 covered by ERBE. Our model computations are in very good agreement with 5-year ERBE scanner measurements, performing better than GCMs and reanalysis products, with a model OSR overestimation of 0.3 and $1.6 \mathrm{Wm}^{-2}$ for the North and South Hemispheres, respectively. The 5-year model computed mean annual global OSR is found to be larger than the ERBE by $0.93 \mathrm{Wm}^{-2}$ (or by $0.92 \%$ ), i.e. within the uncertainties of ERBE. Note that the 14-year (1984-1997) average value of OSR is found to be significantly, by $0.6 \mathrm{Wm}^{-2}$, smaller than the corresponding 5-year (1985-1989) value, because of the inter-annual decreasing trend, discussed in Sect. 4.2.

\subsection{Sensitivity of TOA SW radiation budget}

A series of sensitivity tests were performed with our model, to quantify the role of various physical key parameters that determine the OSR fluxes at TOA. In each test, the relevant parameter, $\mathrm{V}$, was modified by a certain amount, $\Delta \mathrm{V}$, i.e. by $10 \%$ in most cases, in relative percentage terms, and the modification, $\triangle \mathrm{OSR}$, of outgoing $\mathrm{SW}$ radiation at TOA with respect to the defined reference case, was computed and subsequently expressed either in absolute terms (in $\mathrm{Wm}^{-2}$ ) or in relative percentage values. The year 1988 was chosen to represent the reference case. The tests were performed at the monthly and pixel level, but results are also given in terms of globally and annually averaged $\triangle \mathrm{OSR}$ absolute and percentage values. The results of our model sensitivities are valuable for assessing possible sources for the discrepancies obtained between model-computed and ERBE OSR fluxes. The results of our model sensitivity tests indicate that, on a mean annual and global basis, OSR is found to be primarily 
Table 4. Global and annual mean differences $\left(\Delta F_{\uparrow}\right.$ in $\left.\mathrm{Wm}^{-2}\right)$ in model computed outgoing SW radiation at the top-of-atmosphere $\left(F_{\uparrow}\right)$, induced by variation $(\Delta \mathrm{V}$ in relative percentage value, $\%)$ of the variable V ( $A_{c}$, cloud cover; $R_{g}$, surface albedo; ISR, incoming SW radiation at TOA; $\tau_{c}^{S}$, cloud scattering optical depth; $\tau_{c}^{a}$, cloud absorption optical depth; $g_{c}$, cloud asymmetry parameter; $W_{\mathrm{H} 2 \mathrm{O}}$, total precipitable water; $W_{\mathrm{O} 3}$, total ozone column abundance; AOT, aerosol scattering optical depth; $\omega_{\text {aer }}$, aerosol single scattering albedo; $g_{a e r}$, aerosol asymmetry parameter). In parenthesis, is given the range of variation $\left(\Delta F_{\uparrow}\right.$ in $\left.\mathrm{Wm}^{-2}\right)$ of $F_{\uparrow}$ fluxes at pixel $\left(2.5^{\circ}\right.$ latitude-longitude) level, for each sensitivity test. Year 1988 is the reference case.

\begin{tabular}{lcr}
\hline Reference & & 104.78 \\
\hline $\mathrm{V}$ & $\Delta \mathrm{V}$ & $\Delta F_{\uparrow}$ \\
\hline Low- $A_{c}$ & 10 & $2.0(-5.3-13.5)$ \\
Middle- $A_{c}$ & 10 & $1.4(-5.4-9.9)$ \\
High- $A_{c}$ & 10 & $1.6(-4.1-12.3)$ \\
Low- $\tau_{c}^{s}$ & 10 & $1.3(-4.0-5.3)$ \\
Middle- $\tau_{c}^{s}$ & 10 & $0.9(-4.0-3.8)$ \\
High- $\tau_{c}^{s}$ & 10 & $1.2(-4.0-5.5)$ \\
Low- $\tau_{c}^{a}$ & 10 & $-0.4(-4.6-0.5)$ \\
Middle- $\tau_{c}^{a}$ & 10 & $-0.3(-4.9--0.2)$ \\
High- $\tau_{c}^{a}$ & 10 & $-0.2(-4.0--0.1)$ \\
$g_{c}$ & 5 & $-8.8(-26.0--0.2)$ \\
$W_{\mathrm{H} 2 \mathrm{O}}$ & 10 & $-0.2(-3.1-0)$ \\
$W_{\mathrm{O} 3}$ & 10 & $-0.8(-5.0-0)$ \\
$R_{g}$ & 10 & $3.3(-2.2-84.4)$ \\
$\mathrm{ISR}$ & 1 & $1.0(0.1-4.0)$ \\
$\mathrm{AOT}$ & 10 & $0.1(-4.3-0.3)$ \\
$\omega_{\text {aer }}$ & 10 & $0.2(-2.8-6.6)$ \\
$g_{\text {aer }}$ & 10 & $-0.2(-4.8--0.2)$ \\
\hline
\end{tabular}

sensitive to cloud parameters, i.e. cloud cover, cloud optical depth (especially the scattering one), cloud asymmetry parameter, as well as to surface albedo. Modifying $A_{c}$ by $10 \%$, separately for low, middle, or high-level clouds, resulted in modified OSR by up to about $2 \%$; the OSR fluxes are found to be most sensitive to low-level cloud amount. Modification of $\tau_{c}^{s}$ by $10 \%$, for low, mid or high clouds, changed OSR by up to $1.3 \%$, while modifying surface albedo, $R_{g}$, by $10 \%$, changed the OSR flux at TOA by about $3 \%$, on a mean annual and global basis. It is noteworthy that OSR is found to be very sensitive to cloud asymmetry parameter, $g_{c}$, since an increase of $g_{c}$ by $5 \%$, was found to decrease OSR fluxes at TOA by up to about $9 \%$. This highlights the importance of using appropriate $g_{c}$ values in modelling the SW radiation budget at TOA, and justifies the special care that was taken in this study, to choose best possible $g_{c}$ values, as discussed in Sect. 3.3. Besides, it is interesting that changes in incoming solar radiation at TOA by $1 \%$, can lead to a modification of planetary SW reflection to space equal to about $1 \mathrm{Wm}^{-2}$ (or $\approx 1 \%$ ), which is important in terms of climatic changes due to solar variability. The sensitivity of OSR to total precipitable water, is found to be rather small, since $\Delta W_{\mathrm{H} 2 \mathrm{O}}$ equal to $10 \%$ modified the mean annual global OSR by only $0.2 \%$; this justifies the use of either the NCEP/NCAR or ERA-15 ECMWF $W_{\mathrm{H} 2 \mathrm{O}}$ products, without significant impact upon our computed model components of SW radiation budget at TOA. Note that as far as it concerns the sensitivities that are relevant to cloud parameters, the changes of global mean OSR, are ascribed mostly to South Hemisphere, while for the sensitivities concerned with changes in surface albedo, the OSR changes are mostly ascribed to North Hemisphere. Much larger $\triangle$ OSR values, as high as $84 \mathrm{Wm}^{-2}$, are computed on a local scale in our sensitivity tests, as can be seen in Table 4.

\section{Summary and conclusions}

We have used a radiative transfer model and long-term climatological data for various key physical surface and atmospheric parameters, taken from large data bases such as ISCCP-D2, TOVS, GADS, NCEP/NCAR and ECMWF Global Reanalysis projects, to compute the SW radiation budget at TOA for the 14-year period from 1984 to 1997. The model computations were performed on a mean monthly $2.5^{\circ}$ by $2.5^{\circ}$ longitude-latitude pixel resolution, and the results were validated against quality ERBE-S4 scanner data from 1985 to 1989 . In general, the model is able to predict the seasonal and geographical variation of SW fluxes at TOA and planetary albedo, $R_{p}$. The differences between model and ERBE outgoing SW radiation (OSR) at TOA, are mostly within $\pm 10 \mathrm{Wm}^{-2}$, and within $\pm 5 \mathrm{Wm}^{-2}$ over extended regions, i.e. within the uncertainty of ERBE scanner data. Nevertheless, our model underestimates OSR by larger amounts (i.e. up to $40 \mathrm{Wm}^{-2}$ ) along the Antarctica's coastal area and Greenland, as well as over the Arctic, from spring through summer. Uncertainties in cloud properties are assessed to be the most likely source for this model OSR underestimation. Initially, the model overestimated OSR over some mountainous areas, such as Tibetan plateau, Andes or Antarctica's plateau, especially during winter, due to reasons related to sub-grid orography. In this matter, a significant improvement was obtained by applying a correction (reduction) to land-surface albedo over high-altitude mountain areas. The scatter plot between the model computed and ERBE OSR fluxes, shows a bias of $3.7 \mathrm{Wm}^{-2}$, with a relatively small scatter (rms difference equal to $11.5 \mathrm{Wm}^{-2}$ ), indicating a model overestimation of OSR. On a mean annual and global basis, and over the 5-year period from 1985 through 1989, our model agrees well with ERBE, overestimating OSR by $0.93 \mathrm{Wm}^{-2}$ (or $0.92 \%$ ).

The 14-year (1984-1997) model results, indicate that Earth reflects back to space $101.2 \mathrm{Wm}^{-2}$ out of the received $341.5 \mathrm{Wm}^{-2}$, involving a long-term planetary albedo equal to $29.6 \%$. Slightly larger OSR and $R_{p}$ values are computed 
for the southern than northern hemisphere; it is the same with the model-ERBE differences. The linear regression analysis applied to global average of monthly mean incoming $\mathrm{SW}$ radiation at TOA, indicates a very small $\left(0.1 \mathrm{Wm}^{-2}\right)$ decrease with time. In contrast, a significant decreasing trend in OSR over the 14-year study period, equal to $2.3 \mathrm{Wm}^{-2}$, was found. Also, the mean global planetary albedo, $R_{p}$, was found to have decreased by $0.6 \%$ from January 1984 through December 1997. Our preliminary analysis has shown that the decreasing planetary OSR and $R_{p}$ values mostly occur in the Northern Hemisphere, and mainly in the tropical and sub-tropical $\left(20^{\circ} \mathrm{S}-20^{\circ} \mathrm{N}\right)$ areas, as also indicated by satellite observations (Wielicki et al., 2002). We performed a detailed correlation analysis showing that the above longterm decreasing trend in OSR is significantly correlated with low-level cloud cover. There has also been an increase in the solar heating of the low and middle latitudes and a decrease in the solar heating over high-latitude and polar areas; this could be important for atmospheric general circulation and climate, and needs further investigation. The computed global mean OSR anomaly shows great variations reaching values of $4 \mathrm{Wm}^{-2}$, above or below the 14-year mean value. Some interesting features, such as positive and negative OSR anomalies during El Niño and La Niña events, respectively, or during Pinatubo eruption and recovery period, are seen in the model results, whereas significant negative OSR anomalies (decreasing OSR), starting from year 1992, are detected. Finally, a sensitivity analysis was performed to assess the role of various key physical parameters of the Earth-atmosphere system for the SW radiation budget at TOA. The model results indicate that cloud parameters (cloud amount, optical depth, asymmetry parameter) and surface albedo, are the most critical parameters for TOA SW radiation budget, while the role of $W_{\mathrm{H} 2 \mathrm{O}}$ or $W_{\mathrm{O} 3}$ is less important.

Acknowledgements. This research was funded by the European Commission (contract: EVK2-CT-2000-00055) under the Thematic Programme: Preserving the Ecosystem; Key Action 2: Global Change, Climate and Biodiversity. The ISCCP-D2 and ISLSCP data were obtained from the NASA Langley Research Center (LaRC) Atmospheric Sciences Data Center (ASDC). The NCEP/NCAR Global Reanalysis Project data were obtained from the National Oceanic and Atmospheric Administration (NOAA) Cooperative Institute for Research in Environmental Sciences (CIRES) Climate Diagnostics Center, Boulder, Colorado, USA. The ERA-15 ECMWF data were obtained from the Data Ordering Service of ECMWF. The GADS data were obtained from the Meteorological Institute of the University of Munich (http://www. meteo.physik.unimuenchen.de/strahlung/aerosol/aerosol.htm).

Edited by: J. Abbatt

\section{References}

Abbot, C. G. and Fowle, F. E.: Annals of the Astrophysical Observatory of the Smithsonian Institute, Smithsonian Institution, 2, 245, 1908.

Allan, R. P. and Slingo, A.: Can current climate model forcings explain the spatial and temporal signatures of decadal OLR variations?, Geophys. Res. Lett., 29, 45, 1-4, 2002.

Ardanuy, P. E., Stowe, L. L., and Gruber, A.: Shortwave, longwave, and net cloud radiative forcing as determined from Nimbus 7 observations, J. Geophys. Res., 96, 18 537-18 549, 1991.

Ardanuy, P. E., Kyle, H. L., and Hoyt, D.: Global relationships among the earth's radiation budget, cloudiness, volcanic aerosols and surface temperature, J. Climate, 5, 197-208, 1992.

Astronomical Almanac: US Government Printing Office, Washington, D.C., 20 402, 1991.

Barkstrom, B. R.: The Earth radiation budget experiment (ERBE), Bull. Am. Meteorol. Soc., 65, 1110-1185, 1984.

Barkstrom, B. R. and Smith, G. L.: The Earth radiation budget experiment: Science and implementation, Rev. Geophys., 24, 379 390, 1986.

Barkstrom, B., Harrison, E., Smith, G., Green, R., Kibler, J., Cess, R., and ERBE Science Team: Earth Radiation Budget Experiment (ERBE) archival and April 1985 results, Bull. Am. Meteorol. Soc., 70, 1254-1262, 1989.

Bridgman, H. A.: The radiation balance of the Southern Hemisphere, Arch. Meteor. Geophys. Bioklimatol., B17, 325-344, 1969.

Briegleb, B. P., Minnis, P., Ramanathan, V., and Harrison, E.: Comparison of regional clear-sky albedos inferred from satellite observations and model computations, J. Clim. Appl. Meteor., 25, 214-226, 1986.

Budyko, M. I.: Heat balance of the earth's surface, US Weather Bureau Memo. PB131692, 259, 1956.

Chen, C.-T. and Roeckner, E.: Validation of the Earth radiation budget as simulated by the Max Planck Institute for Meteorology general circulation model ECHAM4 using satellite observations of the Earth Radiation Budget Experiment, J. Geophys. Res., 101, 4269-4287, 1996.

D’Almeida, G. A., Koepke, P., and Shettle, E. P.: Atmospheric aerosols: Global climatology and radiative characteristics, A. Deepak Publishing, Hampton, Virginia, USA, 560, 1991.

Darnell, W. L., Staylor, W. F., Gupta, S. K., Ritchey, N. A., and Wilber, A. C.: Seasonal variation of surface radiation budget derived from International Satellite Cloud Climatology Project C1 data, J. Geophys. Res., 97, 15 741-15 760, 1992.

Dickinson, R., Henderson-Sellers, R., and Kennedy, P.: BiosphereAtmosphere Transfer Scheme (BATS) Version 1e as cloupled to the NCAR Community Climate Model, Tech. Note NCAR/TN387+STR, Natl. Cent. For Atmos. Res., Boulder, Colo., 1993.

Dines, W. H.: The heat balance of the atmosphere, Q. J. R. Meteorol. Soc., 43, 151-158, 1917.

Duvel, J.-Ph., Viollier, M., Raberanto, P., et al.: The ScaRab-Resurs Earth radiation budget dataset and first results, Bull. Am. Meteorol. Soc., 82, 1397-1408, 2001.

Ebert, E. E. and Curry, J. A.: A parameterization of ice cloud optical properties for climate models, J. Geophys. Res., 97, 3831-3836, 1992.

Ellis, J. S. and Vonder Haar, T. H.: Zonal average earth radiation budget measurements from satellites for climate studies, Atmos. 
Sci. Rep., 240, Colo. State Univ., Boulder, 1976.

Fouquart, Y., Bonel, B., and Ramaswamy, V.: Intercomparing shortwave radiation codes for climate studies, J. Geophys. Res., 96, 8965-8968, 1991.

Fowler, L. D, Wielicki, B. A., Randal, D. A., Branson, M. D., Gibson, G. G., and Denn, F. M.: Use of a GCM to explore sampling issues in connection with satellite remote sensing of the Earth radiation budget, J. Geophys. Res., 105, 20 757-20 772, 2000.

Frölich, C.: Data on total and spectral solar irradiance, Comments Appl. Opt., 22, 3928, 1983.

Frölich, C. and Lean, J.: The Sun's total irradiance: Cycles, trends and related climatic change uncertainties since 1976, Geophys. Res. Lett., 25, 4377-4380, 1998.

Fu, Q., Baker, M., and Hartmann, D. L.: Tropical cirrus and water vapour feedback: an effective earth infrared iris feedback?, Atmos. Chem. Phys., 2, 31-37, 2002.

Hahn, C. J., Warren, S. G., and London J.: The effect of moonlight on observation of cloud cover at night, and application to cloud climatology, J. Climate, 8, 1429-1446, 1995.

Harshvardhan, J., Randall, D. A., Corsetti, T. G., and Dazlich, D. A.: Earth radiation budget and cloudiness simulations with a general circulation model, J. Atmos. Sci., 46, 1922-1942, 1989.

Hartmann, D. L.: Aerosol-Cloud-Climate Interactions, Radiative effects of clouds on Earth's climate, International Geophysics Series, Vol. 54, P. Hobbs, Acad. Press Inc., 151-173, 1993.

Hartmann, D. L.: Global Physical Climatology, Academic Press, 411, 1994.

Hartmann, D. L., Ramanathan, V., Berroir, A., and Hunt, G. E.: Earth radiation budget data and climate research, Rev. Geophys., 24, 439-468, 1986.

Hartmann, D. L., Moy, A., and Fu, Q.: Tropical convection and the energy balance at the top of atmosphere, J. Climate, 14, 44954511, 2001.

Hatzianastassiou, N. and Vardavas, I.: Shortwave radiation budget of the Northern Hemisphere using International Satellite Cloud Climatology Project and NCEP/NCAR climatological data, J. Geophys. Res., 104, 24 401-24 421, 1999.

Hatzianastassiou, N. and Vardavas, I.: Shortwave radiation budget of the Southern Hemisphere using ISCCP C2 and NCEP/NCAR climatological data, J. Climate, 14, 4319-4329, 2001.

Hatzianastassiou, N., Cleridou, N., and Vardavas, I.: Polar cloud climatologies from ISCCP C2 and D2 datasets, J. Climate, 14, 3851-3862, 2001.

Hatzianastassiou, N., Katsoulis, B., and Vardavas, I.: Global distribution of aerosol direct radiative forcing in the ultraviolet and visible arising under clear skies, Tellus, 56B, 51-71, 2004.

Hatzidimitriou, D., Pavlakis, K., Hatzianastassiou, N., Drakakis, E., and Vardavas, I.: On the decadal increase in the tropical mean outgoing longwave radiation for the period 1984-2000, Atmos. Chem. Phys. Discuss., 4, 2727-2745, 2004.

Henderson-Sellers, A. and Wilson, M. F.: Surface albedo data for climate modelling, Rev. Geophys., 21, 1743-1778, 1983.

Ho, C.-H., Chou, M.-D., and Sui, C.-H.: Comparison of different earth radiation budget experiment data sets over tropical oceans, Int. J. Climatol., 22, 263-270, 2002.

Houghton, H. G.: On the annual mean balance of the Northern Hemisphere, J. Meteor., 11, 1-9, 1954.

Hoyt, D. V.: The radiation and energy budgets of the Earth using both ground-based and satellite-derived values of total cloud cover, NOAA Tech. Rep., ERL 362-ARL 4, 124, 1976.

Hunt, G. E., Kandel, R., and Mecherikunnel, A. T.: A history of presatellite investigations of the earth's radiation budget, Rev. Geophys., 24, 351-356, 1986.

Intergovernmental Panel on Climate Change (IPCC): Climate Change 2001, The Scientific Basis, edited by Houghton, J. T., Ding, Y., Griggs, D. J., et al., Cambridge Univ. Press, New York, 881, 2001.

Irvirne, W. M.: Multiple scattering by large particles, II, Optically thick layers, Astrophys. J., 152, 823-834, 1968.

Jacobowitz, H., Smith, N. L., Howell, H. B., Nagle, F. W., and Hickey, J. R.: The first 18 months of planetary radiation budget measurements from the Nimbus 6 ERB experiment, J. Atmos. Sci., 36, 502-507, 1979.

Jacobowitz, H., Soule, H. V., Kyle, H. L., House, F. B., and the Nimbus 7 ERB Experiment Team: The Earth Radiation Budget (ERB) Experiment: An overview, J. Geophys. Res., 89, 50215038, 1984.

Kandel, R., Viollier, M., Raberanto, P., et al.: The ScaRab earth radiation budget dataset, Bull. Am. Meteorol. Soc., 79, 765-783, 1998.

Kiehl, J. T. and Trenberth, K. E.: Earth's annual global mean energy budget, Bull. Am. Meteorol. Soc., 78, 197-208, 1997.

Kiehl, J. T., Hack, J. J., and Briegleb, B. P.: The simulated earth radiation budget of the National Center for Atmospheric Research community climate model CCM2 and comparisons with the Earth Radiation Budget Experiment (ERBE), J. Atmos. Res., 99, 20 815-20 827, 1994.

Klein, S. A. and Hartmann, D. L.: Spurious changes in the ISCCP data set, Geophys. Res. Lett., 20, 455-458, 1993.

Koepke, P., Hess, M., Schult, I., and Shettle, E. P.: Global aerosol data set. Rep. No 243, Max-Planck Institut für Meteorologie, Hamburg, Germany, 44, 1997.

Kondratyev, K. Y.: Radiation Characteristics of the Atmosphere and the Earth's surface, Amerind., New Delhi, 580, 1973.

Kuhn, M. H.: The role of land ice and snow in climate, In Understanding Climate Change, Geophys. Monogr. Ser., edited by Berger, A., Dickinson, R. E., and Kidson, J. W., American Geophysical Union, Washington, D.C., 52, 17-28, 1989.

Kyle, H. L., Ardanuy, P. E., and Harley, E. J.: The status of the Nimbus-7 Earth Radiation Budget data set, Bull. Am. Meteorol. Soc., 66, 1378-1388, 1985.

Kyle, H. L., Mecherikunnel, A., Ardanuy, P., Lanning, P., Groveman, B., Garret-Gampbell, G., and Vonder Haar, T. H.: A comparison of two major earth radiation budget data sets, J. Geophys. Res., 95, 9951-9970, 1990.

Kyle, H. L., Hickey, J. R., Ardanuy, P. E., et al.: The Nimbus Earth Radiation Budget (ERB) Experiment: 1975 to 1992, Bull. Am. Meteorol. Soc., 74, 815-830, 1993.

Li, Z. and Leighton, H. G.: Global climatologies of solar radiation budgets at the surface and in the atmosphere from 5 years of ERBE data, J. Geophys. Res., 98, 4919-4930, 1993.

Li, Z., Moreau, L., and Arking, A.: On solar energy disposition: A perspective from observation and modelling, Bull. Am. Meteorol. Soc., 78, 53-70, 1997.

Liou, K. N.: Radiation and cloud processes in the atmosphere, Theory, Observation and Modelling, Oxford University Press Inc., 487, 1992.

Liou, K. N.: An introduction to atmospheric radiation, International 
Geophysics Series, Vol. 84, Academic Press, 583, 2002.

Loeb, N. G., Kato, S., and Wielicki, B. A.: Defining top-ofatmosphere flux reference level for earth radiation budget studies, J. Climate, 15, 3301-3309, 2002.

London, J.: A study of the atmospheric heat balance, final report, contract AF 19(122)-165, Coll. Of Eng., N. Y. Univ., New York, 99, 1957.

London, J. and Sasamori, T.: Radiative budget of the atmosphere in Man's Impact on the climate, edited by Mathews, W. H., Kellog, W. W., and Robinson, G. D., M.I.T. Press, Cambridge, Mass, 141-155, 1972.

Ohring, G. and Adler, S.: Some experiments with a zonally averaged climate model, J. Atmos. Sci., 35, 186-205, 1978.

Ohring, G. and Gruber, A.: Satellite radiation observations and climate theory, Adv. Geophys., 25, 237-304, 1983.

Peng, L. I., Chou, M.-D., and Arking, A.: Climate studies with a multi-layer energy balance model, Part I: Model description and sensitivity to the solar constant, J. Atmos. Sci., 39, 2639-2656, 1982.

Raschke, E., Vonder Haar, T. H., Bandeen, W. R., and Pasternak, M.: The annual radiation balance of the Earth-atmosphere system during 1967-70 from NIMBUS 3 measurements, J. Atmos. Sci., 30, 341-364, 1973.

Ridout, J. A., Chertock, B., and Gelaro, R.: Response of a general circulation model to a change in cloud solar forcing: Model feedbacks and comparison with satellite data, J. Atmos. Res., 99, 18 555-18 576, 1994.

Roesch, A., Wild, M., Gilgen, H., and Ohmura, A.: A new snow cover fraction parameterization for the ECHAM4 GCM, Clim. Dyn., 17, 933-946, 2001.

Roesch, A., Wild, M., Pinker, R. and Ohmura, A.: Comparison of surface spectral albedos and their impact on the general circulation model estimated surface climate, J. Geophys. Res., 107, D14, doi:10.1029/2001JD000809, ACL 13-1-ACL 13-8, 2002.

Rossow, W. B. and Lacis, A. A.: Global, seasonal cloud variations from satellite radiance measurements, Part II: Cloud properties and radiative effects, J. Climate, 3, 1204-1253, 1990.

Rossow, W. B. and Schiffer, R. A.: Advances in understanding clouds from ISCCP, Bull. Am. Meteorol. Soc., 80, 2261-2287, 1999.

Rossow, W. B. and Zhang, Y.-C.: Calculation of surface and top of atmosphere radiative fluxes from physical quantities based on ISCCP data sets 2. Validation and first results, J. Geophys. Res., 100, 1167-1197, 1995.

Rossow, W. B., Walker, A. W., Beuschel, D. E., and Roiter, M. D.: International Satellite Cloud Climatology Project (ISCCP), Documentation of new cloud datasets, Wold Meteorol. Org. Geneva, 115, 1996.

Sagan, C. and Pollack, J. B.: Anisotropic nonconservative scattering and the clouds of Venus, J. Geophys. Res., 72, 467-477, 1967.

Sandford, M. C. W., Allan, P. M., Caldwell, M. E., et al.: The geostationary Earth radiation budget (GERB) instrument on EUMETSAT's MSG satellite, Acta. Astron., 53, 909-915, 2003.

Sasamori, T., London, J., and Hoyt, D. V.: Radiation budget of the Southern Hemisphere, Meteor. Monogr., 35, 9-23, 1972.
Schweiger, A. J., Linsay, R. W., Key, J. R., and Francis, J. A.: Arctic clouds in multi-year satellite data sets, Geophys. Res. Lett., 26, 1845-1848, 1999.

Sellers, P. J., Meeson, B. W., Hall, F. G., et al.: Remote sensing of the land surface for studies of global change: Models - algorithms - experiments, Remote. Sens. Environ., 51, 3-26, 1995.

Slingo, A.: A GCM parameterization for the shortwave radiative properties of water clouds, J. Atmos. Sci., 46, 1419-1427, 1989.

Smith, F. A. and Smith, M. R.: Atlas of Earth Radiation Budget Measurements from NIMBUS 7 ERB, 1979-1983, Florida State University, 254, 1990.

Stephens, G. L.: Optical properties of eight water cloud types, Tech. Pap. 36, CSIRO Div. of Atmos. Phys., 254, 1979.

Stephens, G. L., Campbell, G. G., and Vonder Haar, T. H.: Earth Radiation Budgets, J. Geophys. Res., 86, 9739-9760, 1981.

Thekaekara, M. P. and Drummond, A. J.: Standard values for the solar constant and its spectral components, Nature Phys. Sci., 229, 6-9, 1971.

Vardavas, I. and Carver, J. H.: Solar and terrestrial parameterizations for radiative convective models, Planet. Space Sci., 32, 1307-1325, 1984.

Vardavas, I. M. and Koutoulaki, K.: A model for the solar radiation budget of the Norther Hemisphere: Comparison with Earth Radiation Budget Experiment data, J. Geophys. Res., 100, 7303 7314, 1995.

Vonder Haar, T. H. and Suomi, V. E.: Measurements of the earth's radiation budget from satellites during a five-year period, J. Atmos. Sci., 28, 305-314, 1971.

Watanabe, O.: Distribution of surface features of snow cover in Mizuho Plateau, Mem. Natl. Inst. Polar Res., Spec. Issue Jpn., 7, 44-62, 1978.

Wei, X., Hahmann, A. N., Dickinson, R. E., et al.: Comparison of albedos computed by land surface models and evaluation against remotely sensed data, J. Geophys. Res., 106, 20687-20702, 2001.

Wielicki, B. A., Wong, T. M., Allan, R. P., et al.: Evidence for large decadal variability in the tropical mean radiative energy budget, Science, 295, 841-844, 2002.

Wild, M. and Ohmura, A.: The role of clouds and the cloud-free atmosphere in the problem of underestimated absorption of solar radiation in GCM atmospheres, Phys. Chem. Earth, 24B, 261268, 1999.

Wild, M., Ohmura, A., Gilgen, H., Roeckner, E., Giorgetta, M., and Morcrette, J.-J: The disposition of radiative energy in the global climate system: GCM-calculated versus observational estimates, Clim. Dyn., 14, 853-869, 1998.

Willson, R. C.: Total solar irradiance trend during solar cycles 21 and 22, Science, 277, 1963-1965, 1997.

Yang, S.-K., Hou, Y.-T., Miller, A. J., and Campana, K. A.: Evaluation of the earth radiation budet in NCEP-NCAR Reanalysis with ERBE, J. Climate, 12, 477-493, 1999.

Yu, R., Zhang, M., and Cess, R. D.: Analysis of the atmospheric energy budet: A consistency study of available data sets, J. Geophys. Res., 108, 9655-9661, 1999. 